Estudios Geológicos, 68(1)

enero-junio 2012, 57-89

ISSN: $0367-0449$

doi:10.3989/egeol.40336.133

\title{
Contexto geomorfológico y principales rasgos tecnológicos de nuevos yacimientos del Pleistoceno Medio y Superior en el Valle Inferior del Manzanares (Madrid, España)
}

\author{
Geomorphological setting and main technological features of new \\ Middle and Upper Pleistocene sites in the Lower Manzanares River \\ Valley (Madrid, Spain)
}

\author{
P.G. Silva1 , M. López Recio², F. Cuartero³, J. Baena ${ }^{3}$, F. Tapias², I. Manzano \\ D. Martín ${ }^{3}$, J. Morín², E. Roquero ${ }^{4}$
}

\begin{abstract}
RESUMEN
Las intervenciones arqueológicas llevadas a cabo durante los años 1996 en Tafesa, 2005 en el yacimiento Hospital 12 de Octubre y 2006 en la desembocadura del arroyo Butarque (Villaverde-Barrio de Butarque) situados al sur de la ciudad de Madrid (España), han aportado nuevos conjuntos líticos contextualizados estratigráficamente en los depósitos fluviales pleistocenos correspondientes al tramo inferior del valle del río Manzanares. Los yacimientos arqueológicos analizados se sitúan geomorfológicamente en la denominada "Terraza Compleja del Manzanares" (TCMZ), la cual constituye un nivel fluvial engrosado (20-15 m de potencia) situado entre +22-16 m sobre el cauce actual del río, a lo largo de su margen derecha. Este nivel fluvial ha sido tradicionalmente considerado de edad Pleistoceno medio en base a la industria achelense y complejos faunísticos encontrados en sus niveles inferiores. Ciertamente, Tafesa es un yacimiento situado en la parte inferior-media de la terraza de $+22 \mathrm{~m}$ con industria achelense y fauna de Pleistoceno medio. Por el contrario, los niveles superiores de esta misma terraza en los sectores del 12 de Octubre y Villaverde-Butarque se encuentran asociados a industrias del Paleolítico inferior y medio ya pertenecientes al Pleistoceno superior, como sugieren el conjunto de dataciones OSL y TL existentes para la zona. Los datos analizados en este trabajo indican que el desarrollo de este nivel de terraza engrosado comienza durante la parte final de Pleistoceno medio y abarca todo el Estadio Isotópico OIS 5, ya dentro del Pleistoceno superior.
\end{abstract}

Palabras clave: Pleistoceno medio y superior, Paleolítico, geomorfología, terrazas fluviales, río Manzanares, Cuenca de Madrid, España.

\section{ABSTRACT}

The archaeological works developed during the years 1996 in the site of Tafesa, 2005 in the 12 de Octubre Metro Station site and 2006 in the confluence of the Butarque Stream (Villaverde-Barrio de Butarque site) located south of the Madrid City (Spain), have provided new lithic assemblages. These assemblages have been stratigraphically contextualized in the Pleistocene deposits of the Lower Manzanares river valley within the so-called "Manzanares Complex Terrace" (TCMZ). This fluvial terrace constitutes an anomalous thickened $(20-15 \mathrm{~m})$ deposit at $+22-16 \mathrm{~m}$ above the present river thalweg main-

\footnotetext{
1 Departamento de Geología, Universidad de Salamanca. Escuela Politécnica Superior de Ávila. c/ Hornos Caleros, 50, 05003 Ávila. Email: pgsilva@usal.es

2 Departamento de Arqueología, Paleontología y Recursos Culturales. Auditores de Energía y Medio Ambiente, S.A. Avda. Alfonso XIII, 72. 28016 Madrid. Email: mariolopez@ audema.com

3 Departamento de Prehistoria y Arqueología. Universidad Autónoma de Madrid. Campus de Cantoblanco, 28049 Madrid.

Email: javier.baena@uam.es

${ }^{4}$ Departamento de Edafología, ETSI Agrónomos. Universidad Politécnica de Madrid. Ciudad Universitaria s/n, Madrid.

Email: eroquero@upm.es
} 


\begin{abstract}
ly developed along the right (southern) valley margin. This fluvial level has been traditionally considered of middle Pleistocene age on the basis of the acheulian lithics and faunal assemblages typically located within its lower stratigraphic layers. Certainly, the Tafesa is a fluvial terrace site at $+22 \mathrm{~m}$ with acheulian industry and middle Pleistocene faunal remains at its lower sedimentary sequence. However, the upper sedimentary levels of this same terrace in the 12 de Octubre y Villaverde-Butarque sites throw lithic assemblages of the lower and upper Paleolithic belonging to upper Pleistocene, as suggested by the available set of TL and OSL dates for the zone. The analyses developed in this study indicate that the development of this thickened fluvial terrace started during the end of the middle Pleistocene, but also comprise the whole Oxygen Isotopic Stage OIS 5 during the upper Pleistocene.
\end{abstract}

Key words: Middle and upper Pleistocene, Palaeolithic, geomorphology, fluvial terraces, Manzanares river, Madrid Basin, Spain.

\section{Introducción}

Las excavaciones arqueológicas realizadas entre los años 1996 y 2006 en la zona inicial del valle inferior del Manzanares, aguas abajo de la desembocadura del arroyo del Abroñigal (actual Nudo Sur) han aportado nuevos datos sobre los conjuntos líticos contextualizados en los niveles estratigráficos de la denominada "Terraza Compleja del Manzanares" (TCMZ: +16-22 m; Silva, 2003) allí recuperados. En concreto los yacimientos analizados corresponden al solar de la antigua fábrica de Tafesa (coordenadas UTM x: 441395; y: 4467245), a la estación 12 de Octubre de la Línea 3 del metro de Madrid (x: 441042; y: 4469837) y al proyecto de urbanización UZP-1.05 Villaverde-Barrio de Butarque (x: 437908; y: 4467238) situado en la desembocadura del arroyo Butarque (fig. 1). El nivel de terraza analizado es el que domina la margen derecha del valle inferior del Manzanares desde el sur de la ciudad de Madrid hasta su actual desembocadura en el río Jarama y donde tradicionalmente se han detectado numerosos yacimientos arqueopaleontológicos. Estas excavaciones fueron motivadas por la necesidad de realizar estudios arqueopaleontológicos previos a estos proyectos constructivos en el ámbito de las "Terrazas del río Manzanares", declaradas Bien de Interés Cultural (B.I.C.) con categoría arqueológica y paleontológica por la Comunidad de Madrid según Decreto 113/1993 de 25 de noviembre (B.O.C.M.).

La estratigrafía y contextualización geoarqueológica de los yacimientos del 12 de Octubre y Barrio de Butarque, así como las dataciones OSL obtenidas han sido descritas recientemente (Silva et $a l ., 2008)$. En el presente trabajo se incide en el análisis de los conjuntos líticos desde una perspectiva tecnológica (reconstrucción hipotética de cadenas operativas líticas y esquemas diacríticos de talla) para ambos yacimientos, y su comparación con el excavado en 1996 en Tafesa, del cual se dis- pone de información estratigráfica (Silva et al., 1997) y arqueológica (Baena \& Baquedano, 2004; Baena et al., 2010). Los tres yacimientos se encuentran desde un punto de vista geomorfológico situados en el mismo nivel de terraza correspondiente a la Terraza Compleja del Manzanares (TCMZ) de Silva (2003). Avances en el estudio de las industrias líticas recuperadas han ido publicándose desde mediados de la anterior década, tanto para Tafesa (Baena \& Baquedano, 2004), como para los yacimientos del 12 de Octubre y Villaverde-Barrio de Butarque (López Recio et al., 2006, 2007, 2011; Cuartero et al., 2007; Agustí et al., 2009). El objetivo de este trabajo es exponer las características morfotécnicas y tecnológicas generales de estos conjuntos líticos y contextualizarlos en la secuencia cronoestratigráfica del valle inferior del Manzanares siguiendo nuevos modelos conceptuales de índole geomorfológica.

\section{Marco geológico: la Terraza Compleja del Manzanares}

La secuencia general de terrazas del río Manzanares entre La Zarzuela y su desembocadura en el Jarama se compone de trece niveles (Pérez-González, 1982; 1994; Goy et al., 1989): +1-5m (niveles de llanura de inundación), +8-9m (Hipódromo y Culebro), +11-12m, +12-15m (La Gavia), +16-22m (terrazas complejas), $+25-30 \mathrm{~m}$, $+35-40 \mathrm{~m}$ (San Isidro, cota a techo), +44-46m, $+52-54 \mathrm{~m},+60 \mathrm{~m},+68-72 \mathrm{~m}$ (Teleférico), $+80-85 \mathrm{~m}$ y $90-94 m$ (Cerro Garabitas-Casa de Campo). En base a criterios de correlación altimétricos y edáficos, así como en función de los restos faunísticos y líticos documentados, Silva (1988), Goy et al. (1989), Pérez-González (1994) y Pérez-González \& Uribelarrea (2002) atribuyen al Holoceno los niveles de inundación inferiores a los $5 \mathrm{~m}$, al Pleistoceno superior los niveles comprendidos 


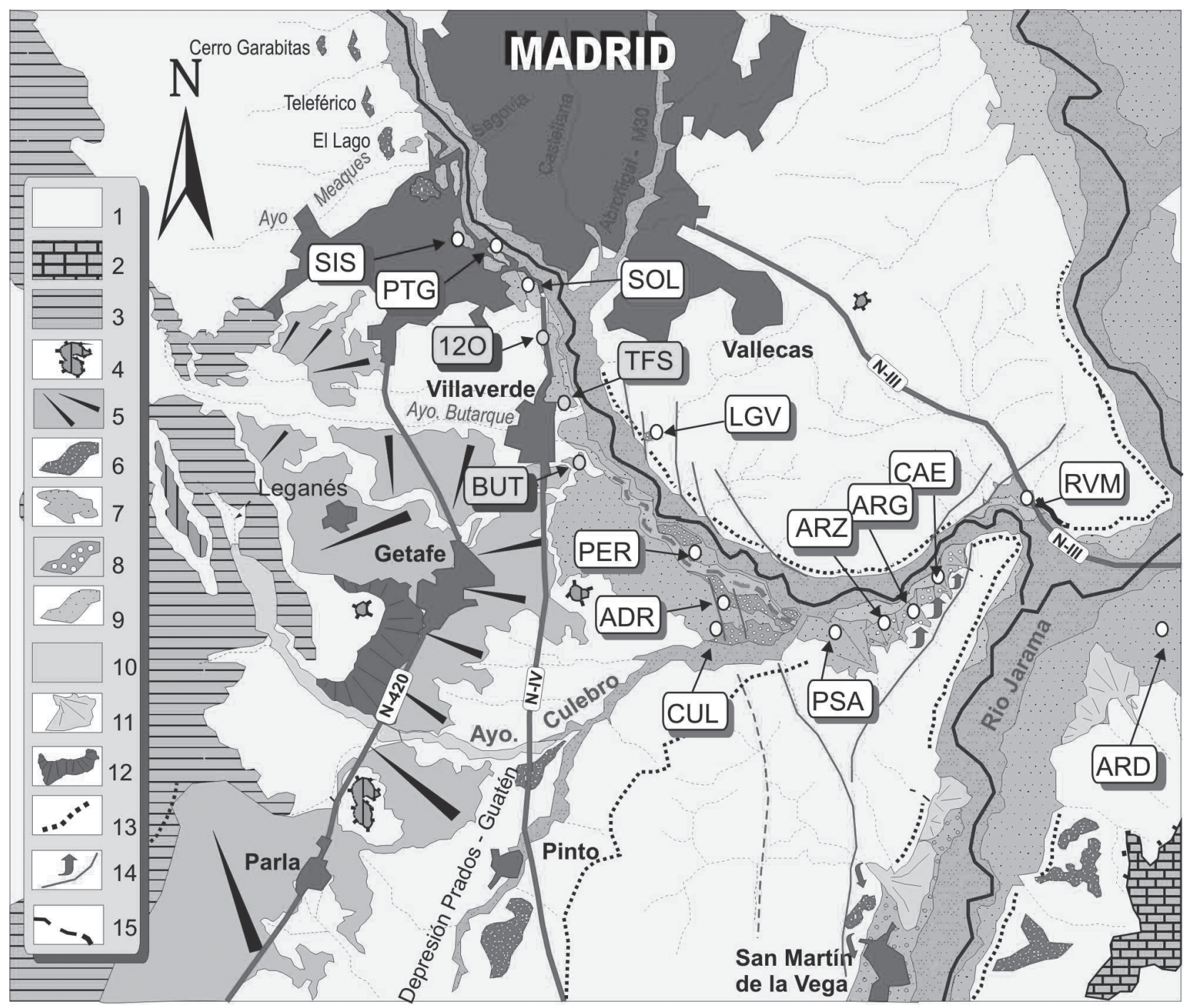

Fig. 1.- Geomorfología y geología del cuaternario del valle del Manzanares mostrando la localización de las excavaciones arqueológicas realizadas en el Hospital 12 de Octubre (12O), Barrio de Butarque (BUT) y Tafesa/Transfesa (TFS), en relación a los principales afloramientos y yacimientos paleontológicos y paleolíticos del entorno urbano de Madrid. SIS (San Isidro), PTG (Portazgo), SOL (Solar de Portazgo), LGV (La Gavia), PER (Perales del Río), ADR (Arenero de Adrián Rosa), CUL (Areneros del Culebro), PSA (PRERESA), ARZ (Arenero de Arcaraz), ARG (Arenero de Arriaga), CAE (Arenero de Casa Eulogio), RVM (Trinchera de RivasVaciamadrid). Leyenda: (1) Superficie del Páramo; (2) Rampa de Griñon-Las Rozas; (3) Cerros testigos; (4) Vertientes de enlace (tipo glacis); (5) Terrazas fluviales del Pleistoceno inferior (incluyendo las de la Depresión Prados-Guatén); (6) Terrazas fluviales del Pleistoceno medio (niveles escalonados de Madrid) y medio-superior (TCMZ: valle inferior del Manzanares); (7) Terrazas fluviales del Pleistoceno superior (niveles Mx); (8) Terrazas fluviales inferiores del Pleistoceno superior-Holoceno; (9) Llanura de inundación actual y niveles escalonados asociados; (10) Abanicos aluviales; (11) Coluviones; (12) Escarpes en yesos; (13) Fallas cuaternarias y zonas de deslizamiento asociadas; (14) valle abandonado; (15) Escalones de erosión remontante en la llanura de inundación actual del Manzanares. Cartografía esquematizada de la elaborada por Silva para la Hoja MAGNA de Getafe (2a edición). Modificado de Silva (2003).

entre $+8 \mathrm{y}+15 \mathrm{~m}$, y al Pleistoceno medio los niveles situados entre +15 y 60 metros. Posteriormente Silva (2003) advierte que la terraza compleja de este sector $(+16-22 \mathrm{~m})$ puede registrar el tránsito entre el Pleistoceno medio y superior. Dataciones OSL recientemente publicadas indican claramente que los niveles superiores de la TCMZ en la zona del 12 de Octubre, Butarque (Silva et al., 2008) y Perales del Río (Pérez-González et al., 2008) presentan edades pertenecientes, e incluso más jóvenes, al Estadio Isotópico OIS 5, ya dentro del Pleistoceno superior. 
El trazado urbano del Manzanares se desarrolla desde la Zarzuela hasta Villaverde Bajo-arroyo del Abroñigal (actual Nudo sur de la M-30) en dirección aproximada N-S. En este tramo el río discurre por las facies arcósicas de borde y arcillo-margosas intermedias del relleno neógeno de la Cuenca de Madrid constituyendo un típico sistema de terrazas escalonadas o encajadas, generalmente de escasa potencia (2-3 m). Por el contrario, en el tramo inferior del Manzanares aguas abajo de la desembocadura del Butarque, el valle describe un brusco giro, tomando una dirección general E-O hasta su desembocadura en el Jarama (fig. 1). El dispositivo de las terrazas fluviales cambia a partir de este punto, pasando a poseer un carácter complejo definido mayoritariamente por niveles de terraza solapados y/o superpuestos anómalamente engrosados siendo el de mayor cota relativa el correspondiente a +25 $30 \mathrm{~m}$ sobre la margen derecha del valle. El siguiente nivel fluvial corresponde al de $+16-22 \mathrm{~m}$ y es el que presenta las mayores secuencias fluviales engrosadas (15-20 m) que Silva (2003) engloba en la denominada "Terraza Compleja del Manzanares" (TCMZ) ya que presenta diferentes dispositivos de solapamiento e incluso yuxtaposición con las terrazas fluviales más recientes en distintos tramos de este sector del valle. El cambio de dispositivo geomorfológico entre ambos sectores del valle está ligado a su entrada en los materiales evaporíticos centrales de la antigua Cuenca Neógena, donde se verifican importantes procesos de subsidencia kárstica que condicionan la sedimentación fluvial e inducen los fenómenos de engrosamiento (PérezGonzález, 1971; 1994; Silva, 2003; Bárez \& PérezGonzález, 2006; Silva et al., 2008; Pérez-González et al., 2008).

El engrosamiento de la TCMZ es importante y en algunos casos se sobrepasan los $20 \mathrm{~m}$ de potencia como muestran los sondeos geotécnicos realizados en la zona de Perales del Río para la construcción de la M-50 (Pérez-González et al., 2008). Los característicos escarpes en yesos del valle inferior tan solo se desarrollan extensamente a partir de la desembocadura del arroyo de La Gavia (Silva et al., 1988b) a lo largo de su margen izquierda (fig. 1). En esta zona del valle sobre los depósitos engrosados de la TCMZ se solapan (Silva et al., 2008) los niveles más recientes de $+12-15 \mathrm{~m},+11-12 \mathrm{~m},+8$ $9 \mathrm{~m}$, tradicionalmente atribuidos al Pleistoceno superior. Como ya se indica desde los trabajos de Obermaier (1925) los niveles situados por debajo de los $+16-15$ m contenían abundante industria muste- riense en las zonas de San Isidro, Usera y Legazpi, aguas arriba de los yacimientos analizados en este estudio, donde presentan el típico dispositivo de terrazas encajadas o escalonadas, claramente individualizadas. Por el contrario, en el sector del valle objeto de este estudio estas terrazas más recientes muestran complejas relaciones de «cut \& fill» entre ellos y con la TCMZ condicionados procesos de subsidencia kárstica y deformación sinsedimentaria (Silva, 2003), dando incluso lugar a procesos de yuxtaposición y superposición de estos niveles fluviales respecto a la TCMZ. Todo ello complica la estratigrafía y diferenciación morfológica individual de los niveles fluviales más recientes en este sector del valle, fundamentalmente aguas abajo de la desembocadura del arroyo Butarque (Silva et al., 2008).

En el ámbito de la TCMZ la compleja estratigrafía cut \& fill que inducen los procesos de solapamiento y yuxtaposición de los niveles fluviales más modernos ha dado lugar a la aparición de conjuntos paleolíticos atribuidos a diferentes complejos tecnológicos aparentemente situados en un mismo nivel de terraza. Esto es especialmente relevante para aquellos conjuntos excavados en este sector del valle con anterioridad a la década de los 80 , que por lo general presentan una contextualización estratigráfica y geomorfológica vaga, imprecisa y a veces ambigua. Además, en algunos casos la presencia de materiales líticos retrabajados procedentes de niveles más antiguos o relacionados con procesos coluvionares de aportes laterales no puede descartarse.

La zona objeto de este estudio se localiza en el segmento de tránsito entre estos dos sectores geomorfológicos del valle (fig. 1), pero ya participa de los fenómenos de engrosamiento característicos del valle inferior del Manzanares. En el sector estudiado muestra una secuencia especialmente compleja en cuanto al ensamblaje geomorfológico de los diferentes niveles de terraza, que además se encuentran afectados por claros fenómenos de deformación sin y post sedimentarios, especialmente importantes en los yacimientos de Tafesa y Butarque (Silva et al., 1997; Silva et al., 2008) y ausentes en el 12 de Octubre. Este último es el yacimiento situado más al norte dentro del sector estudiado y se encuentra sobre las facies arcillosas neógenas (fig. 1), mientras que en los de Tafesa y Butarque el sustrato evaporítico se encuentra a escasa profundidad de la base de las terrazas analizadas.

El cambio en el ensamblaje geomorfológico de los sistemas de terraza está relacionado con la dis- 
tinta litología de las unidades neógenas sobre las que se excavó el valle. Los fenómenos de subsidencia que favorecieron el engrosamiento de la TCMZ, y el solapamiento de niveles más recientes se debe a la alta solubilidad de las facies mayoritariamente evaporíticas por las que discurre el río en este tramo (Pérez-González, 1982; Goy et al., 1989; Silva et al., 1989; Silva, 2003). No obstante, los fenómenos de engrosamiento comienzan a ser patentes ya a partir de la entrada del valle del Manzanares en las facies de arcillas verdosas neógenas en la zona de los antiguos areneros de la terraza de San Isidro, como lo demuestran las potencias de más de diez metros registradas en esta zona durante las excavaciones de principios del siglo XX (Obermaier, 1925). En cualquier caso, este proceso no es exclusivo del Manzanares en el interior de la Cuenca Neógena de Madrid, ya que las terrazas de los ríos Jarama (Pérez-González, 1971), Tajo (Pinilla et al., 1995) y Tajuña (Silva et al., 1988b) muestran engrosamientos y deformaciones similares en aquellas zonas donde estos valles discurren sobre los mencionados materiales evaporíticos de centro de cuenca. Aunque los fenómenos de subsidencia kárstica a gran escala son propuestos por muchos de los autores como el mecanismo primordial que controla el engrosamiento y deformación sinsedimentaria de los depósitos fluviales (Pérez-González, 1971; Pinilla et al., 1995; Silva, 2003; Bárez \& Pérez-González, 2006), en el valle inferior del Manzanares la tectónica cuaternaria se solapa a esta fenomenología kárstica amplificando y/o sosteniendo en el tiempo el proceso de subsidencia que registra la TCMZ (Silva et al., 1997; Silva, 2003; Giner et al., 1996). Por último, señalar que los primeros autores en identificar procesos de deformación sinsedimentaria en las terrazas del Manzanares (niveles deformados de llanura de inundación, convolutas e inyecciones de arena) las atribuyeron a fenómenos de crioturbación (Imperatori, 1955; Riba, 1957; Gaibar Puertas, 1974).

La altimetría de la TCMZ es variable, encontrándose su superficie a cotas relativas desde $+20-22 \mathrm{~m}$, en las cercanías de Villaverde (tramo objeto de estudio), hasta los +16-18m aguas abajo de la desembocadura del Culebro (Silva, 1988; Silva et al., 1989; Gaibar Puertas, 1974). Los depósitos asociados a la TCMZ presentan una estructura interna en la que las distintas unidades fluviales muestran relaciones estratigráficas de tipo "cut \& fill" muy complejas y potencias anómalas que sobrepasan los $20 \mathrm{~m}$. La litología dominante son arenas arcósicas bien selec- cionadas, con proporciones medias del $38,4 \%$ de cuarzo, 39,2\% feldespato potásico y $22,1 \%$ fragmentos de roca (Silva et al., 1997; 1999; Silva, 2003). En la mayor parte de los casos los paquetes arenosos se encuentran culminados por arcillas o arcillas-limosas verdes (gredas) de llanura de inundación que separan diferentes ciclos fluviales. Las facies de gravas de cuarzo, granitoides, sílex y calizas únicamente aparecen como lag basales en las unidades arenosas. Sílex y calizas únicamente comienzan a ser importantes aguas abajo de las desembocaduras de los arroyos Butarque y Culebro, relacionados con la presencia de aportes laterales procedentes de los materiales neógenos que constituyen los relieves adyacentes.

Silva (2003) subdivide la mencionada TCMZ en al menos cinco unidades fluviales superpuestas y/o solapadas, que denomina $\mathrm{Mz}_{1}, \mathrm{Mz}_{2}, \mathrm{Mz}_{3}, \mathrm{Mz}_{4} \mathrm{y}$ $\mathrm{Mz}_{5}$ de más antigua a más moderna. Sobre estos depósitos se solapan o superponen unidades mixtas $(\mathrm{Mx})$, que incorporan en gran proporción aportes laterales fluviales o aluviales de los tributarios del Manzanares por su margen derecha (Silva, 2003). Todas las unidades Mz presentan característicamente secuencias granodecrecientes de arenas en facies de barras y relleno de canal que culminan con los típicos depósitos de arcillas limosas verdes (gredas) de llanura de inundación. Las potencias de las diferentes unidades $\mathrm{Mz}$ oscilan entre los 3 y los $7 \mathrm{~m}$, mostrando una clara tendencia estratodecreciente. No obstante, las unidades $\mathrm{Mz}_{4}$ y $\mathrm{Mz}_{5}$ muestran localmente un carácter erosivo importante pudiendo situarse en neta discordancia erosiva sobre el resto de las unidades $\mathrm{Mz}$, abarcando gran parte de la potencia de los afloramientos. Fuera de estos casos, estas dos últimas unidades poseen por lo general potencias de 2,5-3 $\mathrm{m}$.

A techo de cada unidad $\mathrm{Mz}$ los paquetes de greda suelen mostrar un variable grado de edafización, siendo común el desarrollo de enrejados en los horizontes Ck en las dos unidades superiores, que indica su mayor grado de exposición subaérea. No obstante el grado de evolución edáfica no es muy marcado, siendo característicos horizontes Bt de color pardo rojizo oscuro (2.5YR3/4) con un grado limitado de desarrollo de la estructura. Es a partir de los dos últimos episodios $\mathrm{Mz}_{4} \mathrm{y} \mathrm{Mz}_{5}$, y especialmente del $\mathrm{Mz}_{5}$, donde comienzan a aparecer las características mixtas influenciadas por los aportes laterales de los afluentes, los cuales son especialmente patentes a partir de la confluencia del Butarque (Silva, 1988; 2003). Así, estas dos últimas unidades son 


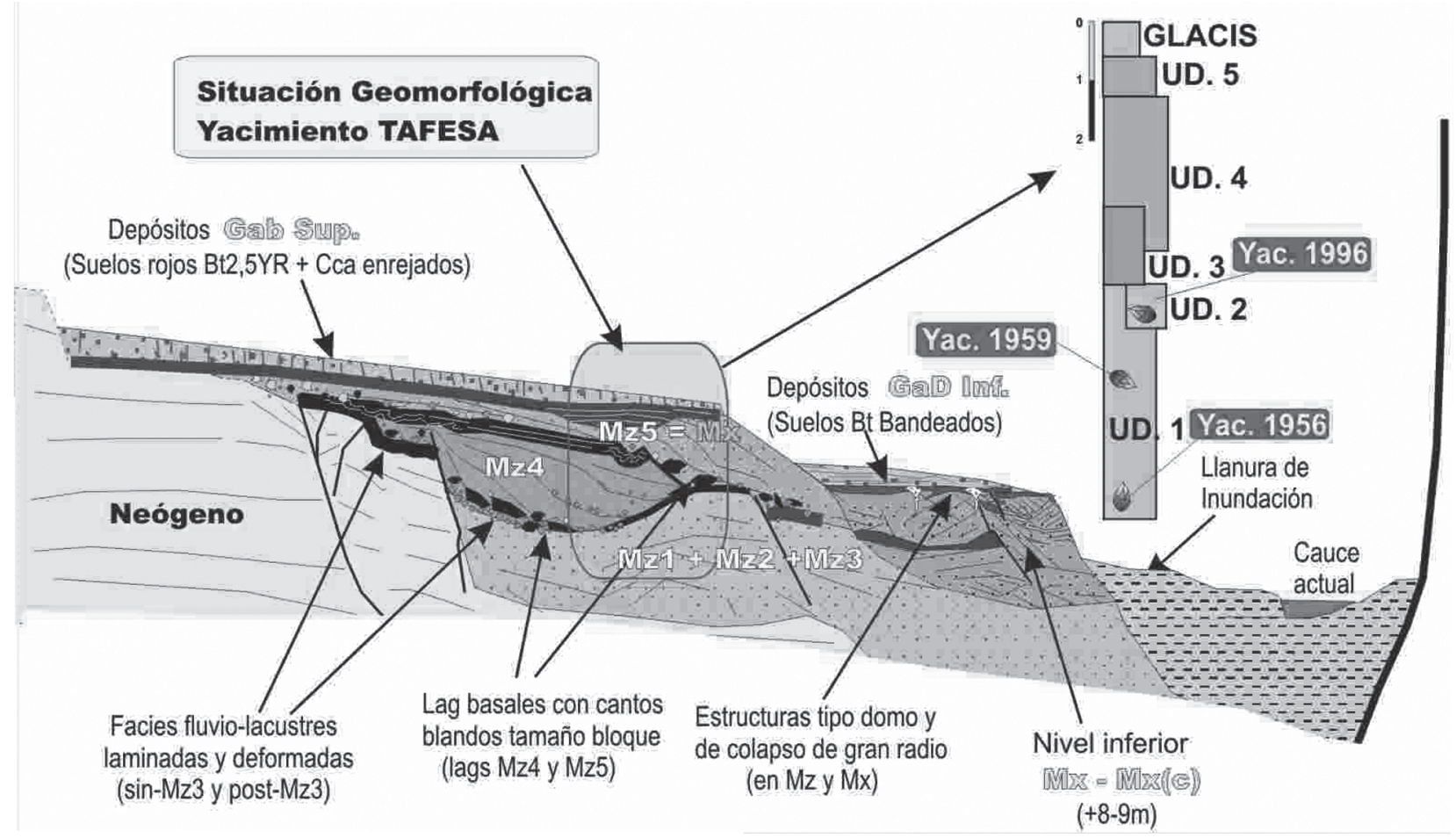

Fig. 2.-Corte esquemático (no a escala) representando las relaciones estratigráficas y geomorfológicas entre las distintas secuencias fluviales que componen la TCMZ (Niveles Mz), niveles de terraza inferiores solapados (niveles Mx), sistemas de glacis y abanicos superiores (GaB Sup), glacis y derrames inferiores (GaD Inf) y llanura de inundación actual del Manzanares para la zona del yacimiento arqueológico y paleontológico de Tafesa (antigua Transfesa). La columna estratigráfica sintética ilustra la posición de los diferentes yacimientos arqueológicos y paleontológicos contextualizados en esta terraza fluvial. La posición vertical de los bifaces indica la localización" in situ" del yacimiento, mientras que los que aparecen volcados indican su naturaleza rodada (resedimentada).

bastante complejas ya que en la mayoría de las ocasiones se encuentran constituidas por un amalgamiento de canales solapados dispuestos en offlap en los que el registro temporal se sucede mayoritariamente en la horizontal, pudiendo incluso llegar a yuxtaponerse entre ellas y solaparse con unidades Mx más recientes (Silva et al., 2008).

La característica más particular de los yacimientos estudiados en este trabajo es que se encuentran en zonas relativamente marginales del valle, adosadas a los relieves limítrofes del mismo. En detalle el yacimiento del 12 de Octubre (el más septentrional de este estudio) se encuentra situado aguas arriba en la zona de "arranque" de la TCMZ sobre el sustrato neógeno. Por otro lado los yacimientos de Tafesa y Villaverde-Butarque se encuentran situados a ambos lados de la desembocadura del arroyo Butarque en el Manzanares aguas arriba y aguas abajo respectivamente (fig. 1). En todos los casos es posible ver, o inferir, las relaciones de los depósitos fluviales analizados con los materiales neógenos a los que se superponen, advirtiéndose un claro engrosa- miento de los depósitos fluviales estudiados desde el NO al SE.

\section{Yacimiento de Tafesa}

\section{Situación geomorfológica y secuencia sedimentaria}

El yacimiento de Tafesa (denominado a mediados del siglo XX "Transfesa") se localiza en la terraza situada a +22m (Silva et al., 1997; Silva, 2003), en la margen derecha del río Manzanares. Esta terraza ha sido tradicionalmente asignada al Pleistoceno medio en base a su altimetría y a la fauna (Elephas antiquus, Bovidae indet., Cervus sp., Equus caballus, Sus cf. scrofa y Praedama sp.) aparecida en las excavaciones realizadas durante los años 1956 y 1957 (Meléndez \& Aguirre, 1957 y 1958; Andrés \& Aguirre, 1974; Soto \& Sesé, 1987; Aguirre, 1989; Sesé \& Soto, 2000; fig. 2). Este enclave presenta unos depósitos fluviales con una potencia cercana a 


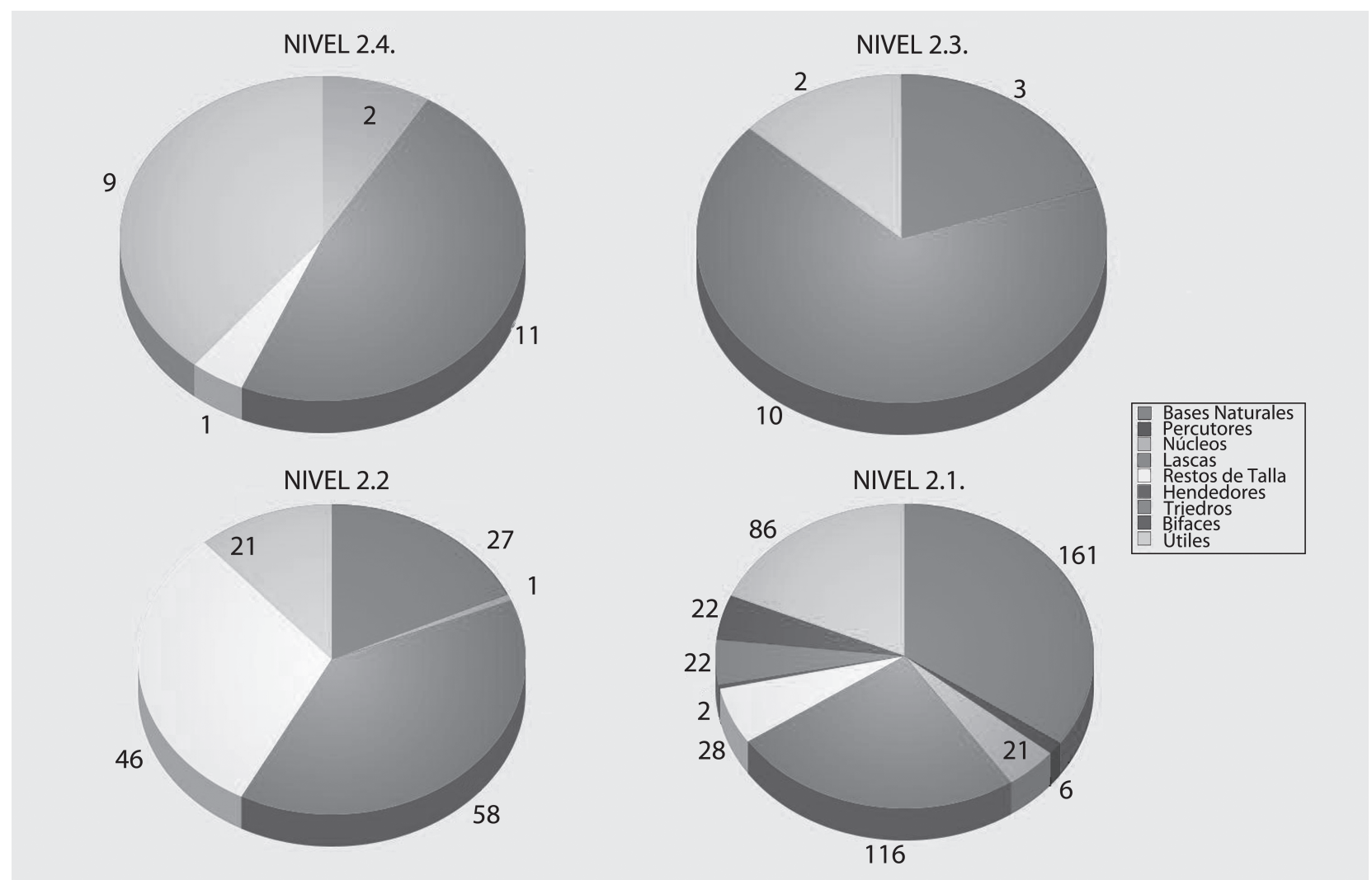

Fig. 3.-Categorías morfotécnicas del yacimiento de Tafesa por niveles estratigráficos dentro de la Unidad 2 (relleno de canal) de la excavación (valores absolutos).

los $8 \mathrm{~m}$, en los que se pueden diferenciar al menos ocho unidades sedimentarias. Éstas presentan diferente naturaleza (arenas arcósicas de tamaño mediofino, medio a grueso y grueso, arcillas, limos y lag de gravas), tendencia granodecreciente, encontrándose separadas por superficies de erosión bastante netas (Sánchez et al., 1996; Silva et al., 1997).

La excavación del solar de Tafesa se realizó en 1996 sobre una extensión de $30 \mathrm{~m}^{2}$ en un nivel denominado unidad estratigráfica 2 , correspondiente a un relleno de canal plano cuya base contiene la industria lítica y los restos paleontológicos recuperados (Baena \& Baquedano, 2004; Baena et al., 2010). Se trata de un depósito de $0,70-0,65 \mathrm{~m}$ de potencia compuesto por arenas arcillosas y arcillas arenosas con lag basal de cantos encajado en las facies de llanura de inundación que culminan la unidad 1 de la excavación (fig. 2). Las facies de gravas y arenas basales de la unidad 1 es la que contenía los antiguos yacimientos de mediados de siglo XX (fig. 2). Estas dos unidades estratigráficas se corresponden con las secuencias sedimentarias $\mathrm{Mz}_{1}$ y $\mathrm{Mz}_{2}$ de Silva (2003) respectivamente (fig. 2). El yacimiento arqueológico excavado en 1996 se contextualiza en la base del canal que constituye la unidad 2, el cual se encuentra estructurado en 4 niveles sedimentarios diferentes. El análisis de la geometría y sedimentología de los depósitos del relleno de canal indican que éste corresponde a un meandro abandonado por un proceso de estrangulamiento (Silva et al., 1997).

\section{Descripción y características tecnológicas de la industria lítica}

Las principales categorías registradas en el yacimiento comprenden 211 restos óseos y 651 líticos. El yacimiento presenta cuatro niveles estratigráficos incluidos en la unidad $\mathrm{Mz}_{2}$ de la TCMZ (fig. 3), siendo el nivel 2.1 (basal) donde se contextualiza la mayoría del registro lítico y faunístico. El nivel 2.1 contiene 464 piezas, el nivel 2.2149 , el nivel 2.315 y el nivel 2.4 tan solo 23. Se incluyen en el cómputo los nódulos/bases naturales (concepto definido en Carbonell et al., 1983) de sílex, no existiendo en el nivel 2.4 y siendo 3 para el nivel 2.3, 27 para el 

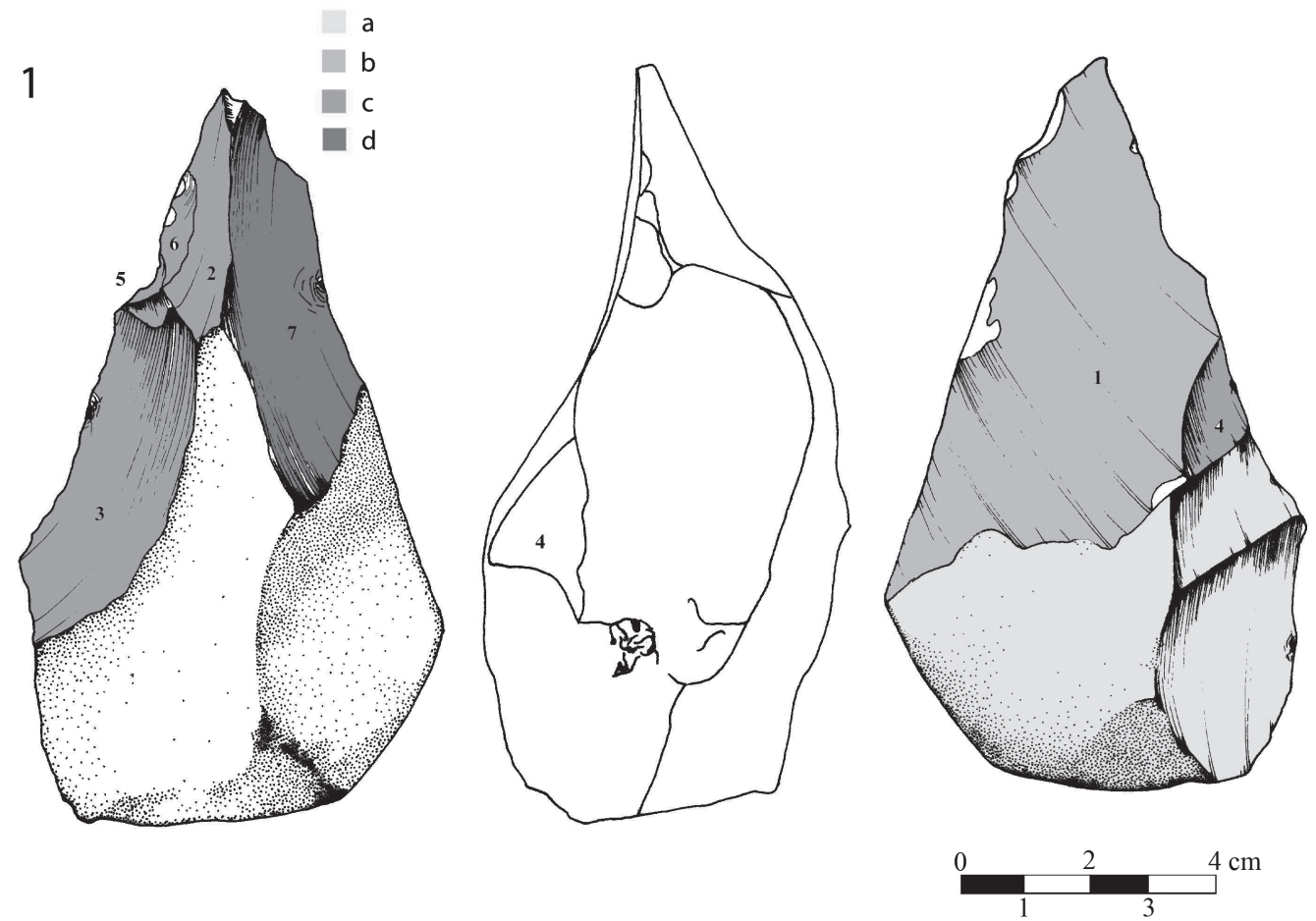

2
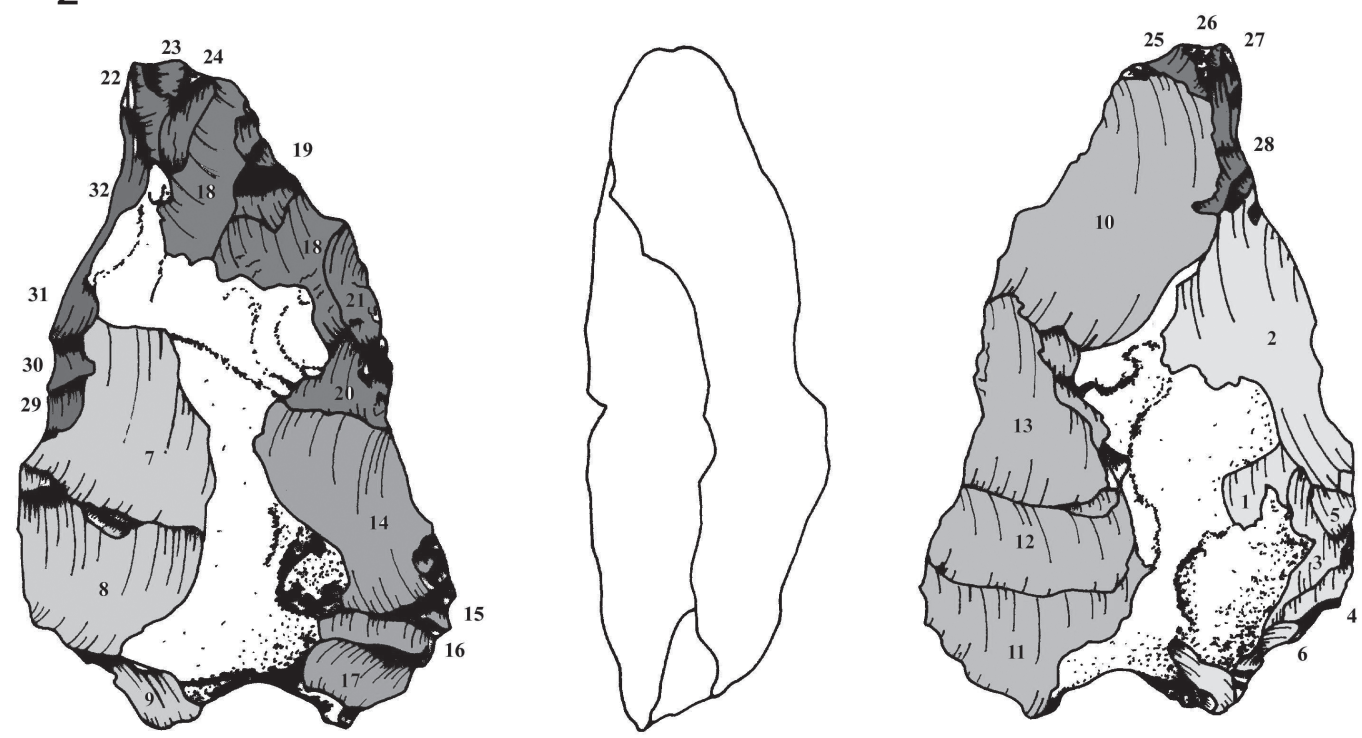

$1^{a}$
$2^{a}$
$3^{a}$
$4^{a}$
$5^{a}$
$6^{a}$
$7^{a}$

Fig. 4.-Esquemas diacríticos característicos de façonnage (triedro y bifaz) del yacimiento de Tafesa (orden de las series según escala cromática adyacente): 1) Triedro: a) soporte y extracciones rodadas, b) adelgazamiento de base, c) serie escasamente alternante, d) extracción final; 2) Bifaz: $1^{\mathrm{a}}$ serie (no alternante), $2^{\mathrm{a}}$ serie (no alternante), $3^{\mathrm{a}}$ serie (no alternante), $4^{\mathrm{a}}$ serie (no alternante), $5^{\circ}$ serie (no alternante), $6^{a}$ serie de configuración del extremo, $7^{\mathrm{a}}$ serie de configuración lateral. 

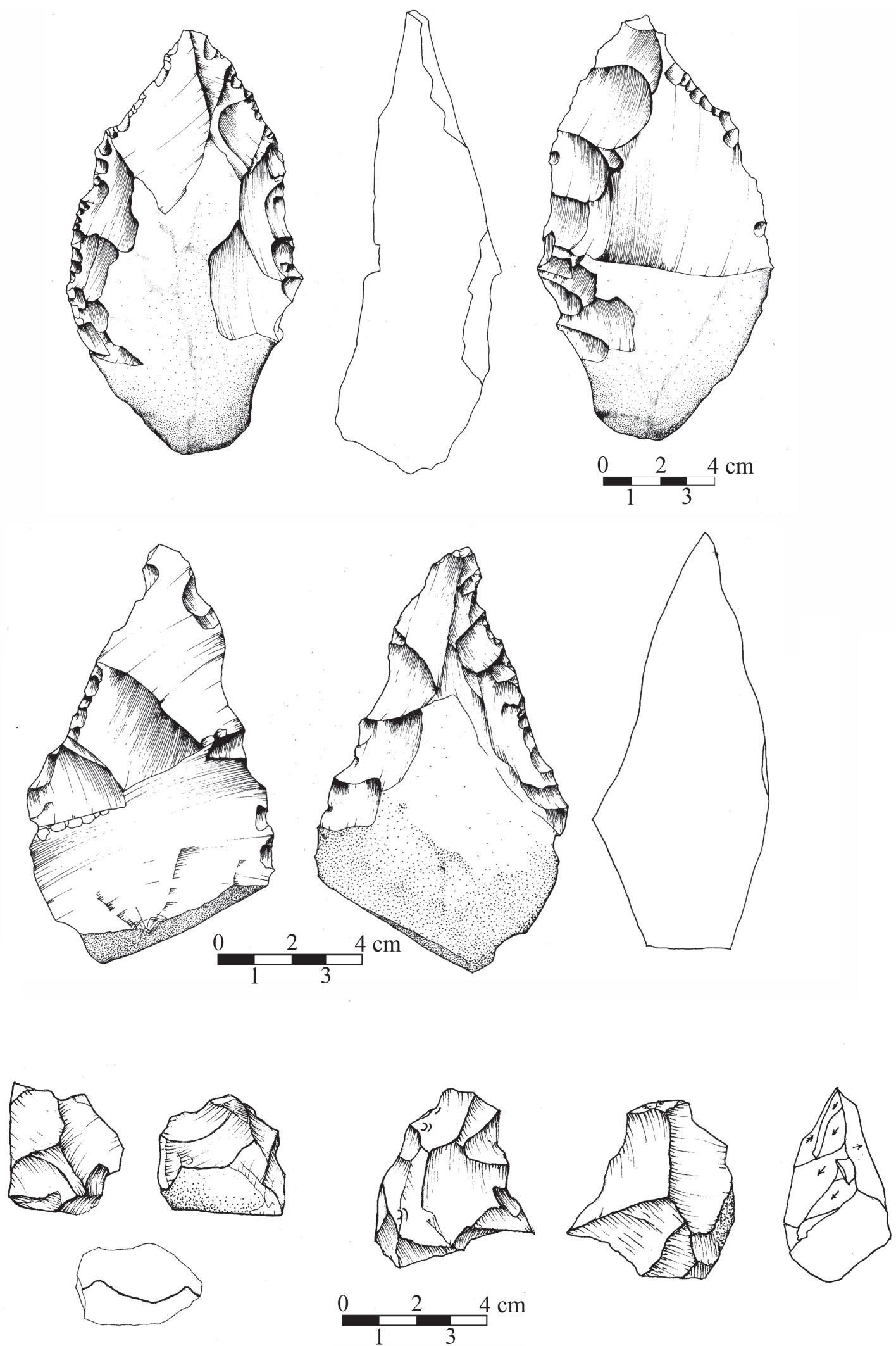

Fig. 5.-Industria lítica del yacimiento de Tafesa (Madrid): Bifaz sobre lasca; triedro sobre lasca y núcleos. 


\begin{tabular}{lccccccccc}
\hline & $\begin{array}{c}\text { Bases } \\
\text { naturales }\end{array}$ & Percutores & Núcleos & Lascas & $\begin{array}{c}\text { Restos de } \\
\text { Talla }\end{array}$ & Hendedores & Triedros & Bifaces & Útiles \\
\hline Número & 161 & 6 & 21 & 116 & 28 & 2 & 22 & 22 & 86 \\
\hline Volumen & 451.7 & 518.9 & 146.6 & 93.4 & 72.3 & 377.7 & 343 & 328.4 & 48.3 \\
\hline
\end{tabular}

Fig. 6.-Análisis dimensional por categorías morfotécnicas del nivel 2.1 de Tafesa.

nivel 2.2 y 161 para el nivel 2.1. Los datos más significativos referentes a la industria lítica de Tafesa se centran, fundamentalmente, en la representatividad de la muestra perteneciente al nivel 2.1 del yacimiento. La industria lítica presenta como rasgos generales características similares a otros conjuntos documentados anteriormente en contextos de carácter fluvial del ámbito de la cuenca media del Tajo (Querol \& Santonja, 1979; Baena et al., 2000), con presencia de macroutillaje (façonnage) junto a un número importante de lascas, algunas retocadas. Destaca, a grandes rasgos, la relativa estandarización volumétrica del macroutillaje junto a la escasa representación del utillaje retocado respecto al de la categoría lascas. Esta diferencia acredita la existencia dentro de estas últimas de productos de muy diferente procedencia (lascas producto de façonna$g e$, frente a productos de débitage).

Los modelos de captación de la materia prima son expeditivos y de claro carácter local, a partir de depósitos secundarios de origen fluvial, documentado para el contexto del Manzanares (Rus \& Enamorado, 1991; Conde et al., 2000). Las materias primas empleadas en el conjunto lítico del nivel 2.1 son el sílex (285 restos), el cuarzo (127 restos) y en menor medida la cuarcita (51 restos), alóctona a los niveles fluviales del Manzanares. La composición del macroutillaje en el nivel 2.1 es de 22 bifaces ( 3 ficrones, 2 amigdaloides, 2 abbevillenses, 2 diversos, 4 esbozos y 9 parciales), 22 triedros y 2 hendedores. En cuanto a la configuración de macroutillaje o façonnage, las modalidades varían en función del soporte de partida, distinguiéndose diferentes estrategias según se parta de grandes lascas, nódulos ortogonales o fragmentos de nódulos, placas o tabletas, paleo-industrias (piezas líticas más antiguas reaprovechadas) o de nódulos/bases naturales de morfología cercana al producto buscado (se aprecia una selección en la recogida de soportes de morfologías específicas para la obtención de bifaces y triedros). Mediante estas modalidades se confeccionaron bifaces y triedros espesos de aristas sinuosas y morfologías poco simétricas (figs. 4 y 5).
Con respecto a la producción de lascas o débitage, los esquemas o modalidades de explotación identificados son los siguientes: Modalidad 1: explotaciones a partir de soportes de morfología ortogonales con explotaciones periféricas desde un plano de percusión dominante (Santonja, 1984-85; Mosquera, 1989); Modalidad 2: explotaciones a partir de soportes con tendencia discoide parcial sobre un plano de percusión en el que se trabaja de forma más o menos alternante (Peresani, 2003); Modalidad 3: núcleos con explotaciones de morfologías ortogonales organizadas en torno a múltiples planos de explotación; y Modalidad 4: explotaciones de carácter bifacial mediante series escasamente alternantes, de morfología aplanada.

Es de destacar que los núcleos analizados (ej. fig. 5 , parte inferior) carecen de una programación (predeterminación) de los productos de lascado siguiendo alguno de los esquemas más frecuentes documentados para el Paleolítico inferior y medio del occidente europeo, tales como el débitage levallois (Boëda, 1994), Quina (Turq, 1989; Bourguignon, 1996), clactoniense (Forestier, 1993), Les Tares (Geneste \& Plisson, 1996) o Le Pucheuil (Delagnes, 1997) lo que confirma el carácter expeditivo del conjunto. En muchos casos podría tratarse de fases iniciales en la producción de macroutillaje, lo cual no invalida la existencia de verdaderas explotaciones dirigidas a la producción de lascas como tales o como bases para la confección de utillaje retocado. El número de utillaje retocado es reducido (85 piezas), existiendo dos conjuntos diferenciados: por un lado piezas sobre soportes de grandes dimensiones compatibles con productos vinculados con la creación incipiente de grandes lascas, y por otro lado productos de menores dimensiones relacionados con fases avanzadas de la configuración y la propia explotación sobre núcleos (fig. 6). Lo que se observa es que las propias lascas procedentes de la talla de macroutillaje (bifaces principalmente) sirvieron de soportes para el utillaje retocado o como útiles directos (lascas con filo). Dentro de la categoría de útiles destaca la heterogeneidad del registro, con predominio del conjunto de denticulados, escotadu- 


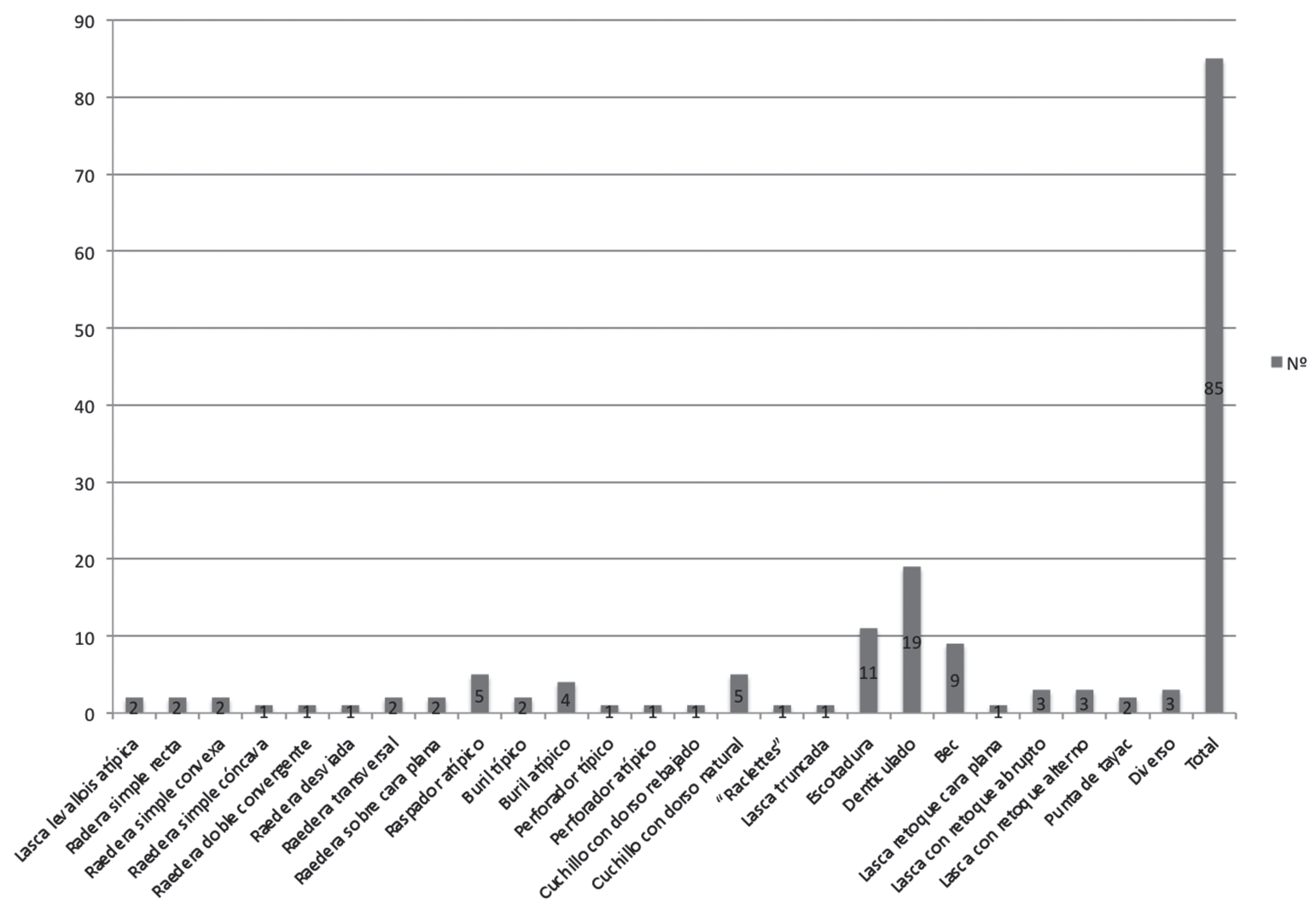

Fig. 7.-Lista tipológica de piezas líticas documentadas en el yacimiento arqueológico de Tafesa excavado en el año 1996 (valores absolutos).

ras, muescas y becs (fig. 7), advirtiéndose de que las delineaciones denticulantes son frecuentemente resultado de procesos funcionales o postdeposicionales en medios fluviales (Tringham et al., 1974; Prost, 1988). En cuanto a diferenciaciones por dimensiones, existen dos conjuntos, el primero compuesto por utillaje de pequeñas dimensiones representado básicamente por buriles, perforadores, raspadores y elementos de retoque variable (diversos), y el segundo por cuchillos, grandes lascas retocadas, denticulados y raederas configurados sobre soportes de grandes dimensiones.

\section{Yacimiento del Hospital 12 de Octubre}

\section{Situación geomorfológica y secuencia sedimentaria}

La zona del Hospital 12 de Octubre se encuentra en el arranque aguas arriba de la TCMZ frente a la confluencia del arroyo del Abroñigal (fig. 1). El sector excavado se encuentra a una cota de +21$22 \mathrm{~m}$, sin embargo el techo de los depósitos fluviales se encuentra a $+18 \mathrm{~m}$ sobre el Manzanares debido a que están cubiertos por un depósito de glacis de 1,5-2,0 m de potencia. Así, la potencia total del depósito estudiado oscila entre los 5,3 - 6,0 m, pero solo los 3,8-4,0 $\mathrm{m}$ inferiores responden a depósitos fluviales s.s. (fig. 8A).

En este sector se diferencian 4 unidades estratigráficas (fig. 8A). Las tres más antiguas (inferior, intermedia y superior) representan secuencias granodecrecientes asociadas a facies de acreción lateral y relleno de canales meandriformes. La unidad más reciente, situada a techo, responde a la superposición de aportes laterales de tipo glacis. Las facies basales de gravas de la unidad inferior (nivel 1.1) representan barras de acreción lateral de un canal meandriforme de dirección NNE y contiene industria lítica rodada asociada a la presencia de cantos blandos del sustrato neógeno y facies de llanura de inundación (Silva et al., 2008). Este tipo de facies de acreción lateral con dominio de granulometrías 


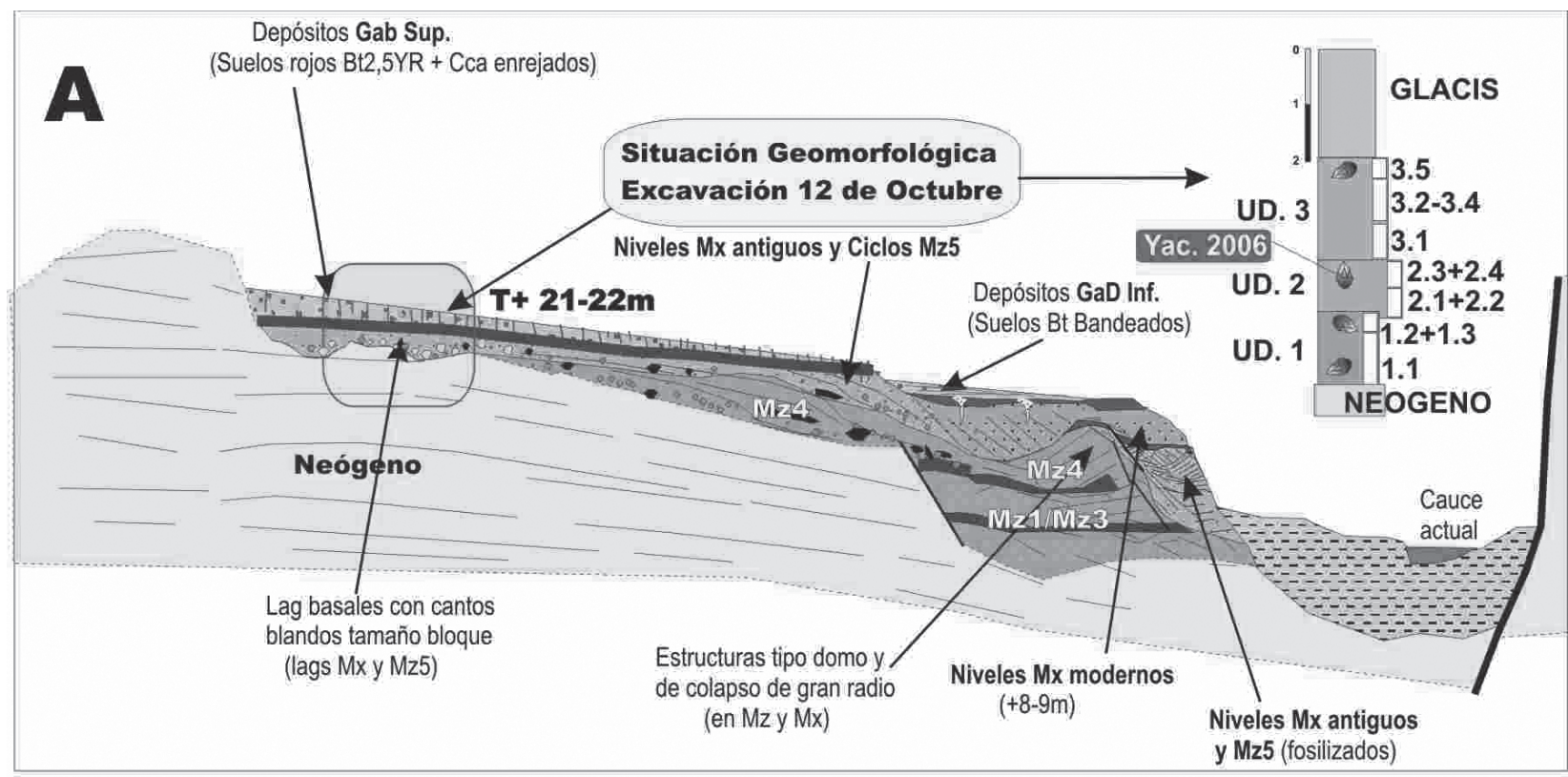

B

Depósitos Gab Sup.

(Suelos rojos Bt2,5YR + Ck enrejados)

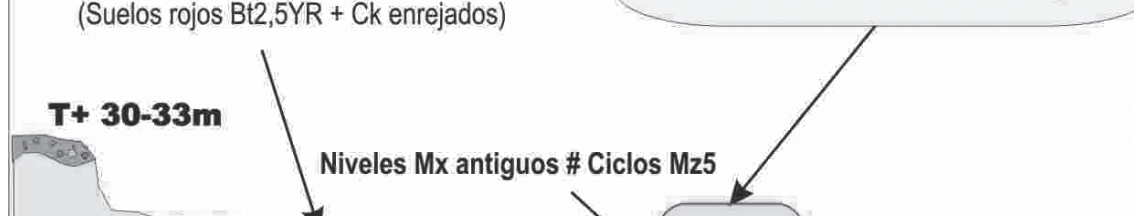

\section{Excavaciones del Butarque}

$T+22-24 m$

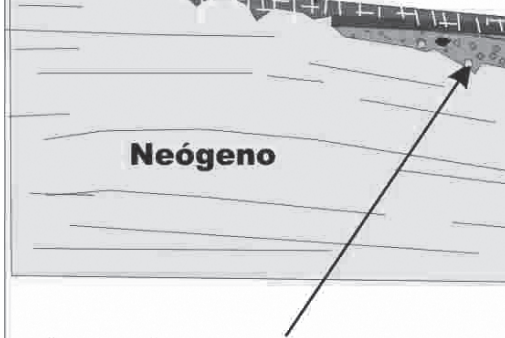

Lag basales con cantos blandos tamaño bloque (lags Mz4 y Mz5)
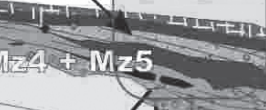

Relleno Holoceno

Llanura aluvial del Arroyo Butarque

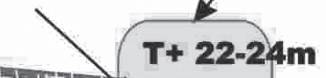

$T+15 m$

$T+20-18 m$

UD. 1

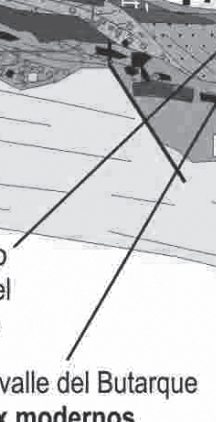

Depósitos Paleovalle del Butarq
Niveles Mx modernos

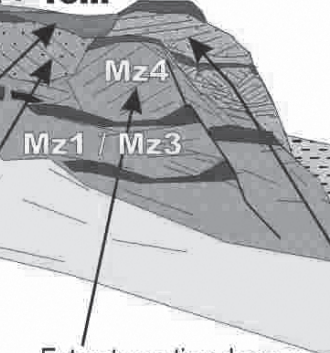

Estructuras tipo domo y de colapso de gran radio (en Mz y Mx)
Llanura de Inundación
LACIS

3.2

3.1

2.2 NEOGENO

Cauce

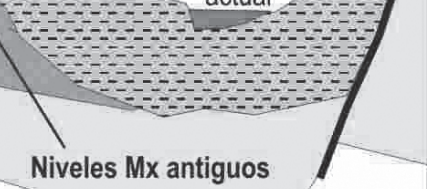

Niveles Mx antiguos

Fig. 8.-Cortes esquemáticos (no a escala) representando las relaciones estratigráficas y geomorfológicas entre las distintas secuencias fluviales que componen la TCMZ (Niveles Mz), niveles de terraza inferiores solapados (niveles Mx), sistemas de glacis y abanicos superiores (GaB Sup), glacis y derrames inferiores (GaD Inf) y llanuras de inundación actuales del Manzanares y Butarque, para la zona del 12 de Octubre (A) y la desembocadura del Butarque en Villaverde Bajo (B). Las columnas estratigráficas sintéticas ilustran en cada caso la posición de los diferentes yacimientos arqueológicos y paleontológicos contextualizados en estas terrazas fluviales. La posición vertical de los bifaces indica la localización" in situ" del yacimiento, mientras que los que aparecen volcados indican su naturaleza rodada (resedimentada). 
de mayor tamaño (arenas gruesas y gravas) y abundante presencia de cantos blandos comienzan a ser patentes en el valle inferior del Manzanares a partir de la unidad $\mathrm{Mz}_{4}$ (Silva, 2003). Los depósitos situados a techo de esta unidad inferior (niveles $1.2 \mathrm{y}$ 1.3) representan un relleno de canal abandonado (dimensiones 4,8 x 0,7 m) el cual contiene una parte de la industria lítica estudiada. Los depósitos excavados responden fundamentalmente a facies de barras y rellenos de canal con gravas y arenas de tamaño medio a grueso. Las unidades 2 y 3 muestran características sedimentológicas semejantes, siendo también relevantes las estructuras de acreción lateral, encontrándose más del $60 \%$ del repertorio lítico documentado asociado a los niveles estratigráficos del techo de la unidad 2 (niveles 2.3 y 2.4). No obstante, en el conjunto de unidades estratigráficas diferenciadas en la excavación se observa una práctica ausencia de niveles arcillosos de llanura de inundación (gredas) que posean un alto grado de desarrollo edáfico (suelos rojos y pardo-rojizos) y ello hace difícil correlacionarlas con las secuencias fluviales individuales de tipo $\mathrm{Mz}$ definidas por Silva (2003). Tan solo a techo de los depósitos de glacis culminantes (unidad 4) se observa un nivel de arcillas verdes masivo $(50-70 \mathrm{~cm}$ de potencia), con un cierto grado de desarrollo edáfico, el cual representa el techo físico real $(+22 \mathrm{~m})$ de la terraza analizada (Silva et al., 2008).

Este nivel de terraza se encaja en la superficie de tipo glacis, perteneciente a los retazos, ya muy disectados, del denominado "Glacis de Carabanchel" definido por Goy et al. (1989; fig. 1). En el sector del 12 de Octubre no se ha identificado ningún nivel de terraza a mayor cota que el analizado en este estudio. La posición culminante de esta terraza en el sector del valle analizado, su fosilización por un único depósito lateral de tipo glacis y características sedimentológicas, permitieron correlacionar este nivel con una de las diferentes unidades yuxtapuestas que componen el ciclo $\mathrm{Mz}_{5}$ o ya los depósitos solapados de tipo Mx (Silva et al., 2008; fig. 8A). Solo la unidad inferior de la excavación (unidad 1) podría tentativamente correlacionarse con la secuencia $\mathrm{Mz}_{4}$ de Silva (2003).

\section{Descripción y características tecnológicas de la industria lítica}

Durante la excavación arqueológica y paleontológica se registró un amplio conjunto lítico compuesto por 1.875 piezas en los diferentes niveles estratigráficos (fig. 9). La mayoría de las piezas han aparecido en los niveles de gravas superiores pertenecientes a la unidad 2, así como en los niveles basales de arenas y gravas con cantos blandos de la unidad 1 . En el nivel de relleno de canal, situado a techo de la unidad 1, se recuperaron 9 piezas con un grado de rodamiento mínimo, con presencia de lascas de sílex e incluso un resto de talla de pequeñas dimensiones, que pueden considerarse "in situ" o ligeramente removilizadas. Los elementos líticos recuperados en otros niveles presentan cierto grado de rodamiento y pueden considerarse en posición secundaria. La mayor parte de la industria lítica recogida y clasificada se relaciona con la base de la unidad 2 que fosiliza el nivel de colmatación del canal situado a techo de la unidad 1 (fig. 8A). A continuación se enumeran las categorías morfotécnicas documentadas por niveles estratigráficos (López Recio et al., 2011), de muro a techo son los siguientes (fig. 9), con indicación del utillaje (fig. 10):

En el nivel 1.1 (niveles basales de gravas) se documentaron 144 piezas líticas: 14 núcleos, 19 restos de talla, 32 lascas simples (sin reservas de córtex), 3 lascas de primer orden (corticales), 22 lascas de segundo orden (semicorticales), una lasca laminar, 43 fragmentos de lasca, 7 lasquitas y entre los útiles destaca la presencia de un bifaz y dos raederas (una doble convergente y una simple recta).

En el nivel 1.2 (canal abandonado), compuesto por arenas medias y gruesas, se documentan 148 piezas líticas, repartidas en 11 núcleos (1 es fragmento), 26 restos de talla, 25 lascas simples, 16 lascas de segundo orden, 5 lascas laminares, 49 fragmentos de lasca, 8 lasquitas (dos son fragmentos), una laminita, una lasca levallois, un bec, un bifaz, un cuchillo de dorso, una raedera simple recta y un fragmento de raedera simple recta. El techo de este canal (nivel 1.3), correspondiente a los limos de relleno de canal situados a techo, cuenta con un escaso número de piezas que corresponden a lascas $\mathrm{y}$ un desecho de talla de reducidas dimensiones.

El segundo tramo estratigráfico con mayor número de piezas conservadas es el techo de la unidad intermedia (niveles 2.3 y 2.4). El nivel 2.3 está caracterizado por una elevada presencia de cantos blandos, con 447 piezas: se recuperaron 58 núcleos (6 fragmentados) y 52 restos de talla, frente un gran número de lascas. Se han contabilizado 102 lascas simples, 3 lascas de primer orden, 91 lascas de 

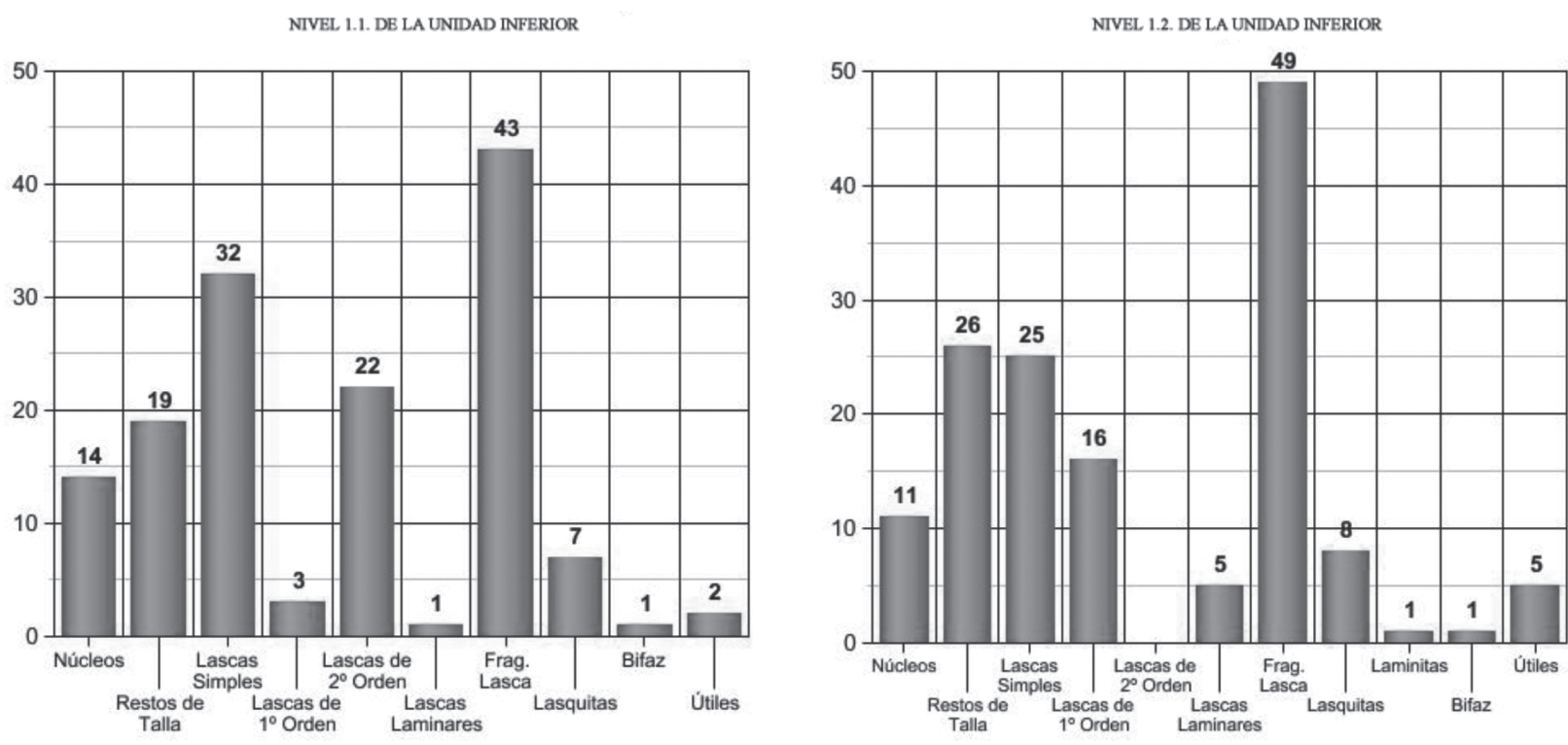

NIVEL 2.3. DE LA UNIDAD INTERMEDIA
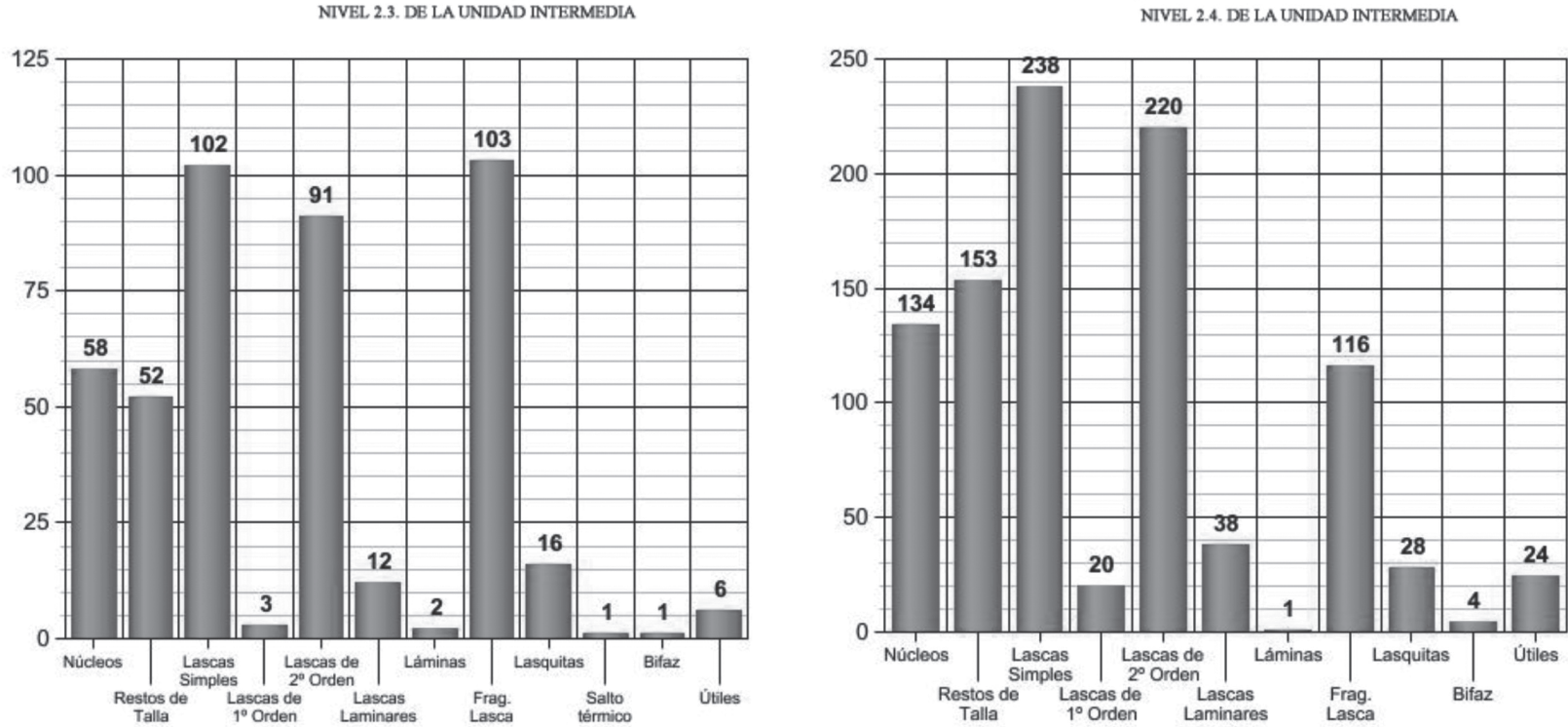

Fig. 9.-Categorías morfotécnicas de los niveles estratigráficos más representativos documentados en el yacimiento del 12 de Octubre (Línea 3 Metro de Madrid) durante las excavaciones realizadas en el año 2005 (valores absolutos).

segundo orden, 103 fragmentos de lasca, 12 lascas laminares, 16 lasquitas y una lasca producida por salto térmico. Por otro lado, se han registrado dos láminas (una fragmentada), así como una serie de utillaje compuesto por un bifaz, una escotadura, una punta levallois atípica y cuatro raederas: una raedera simple, una simple recta, una transversal y otra de tipo semiquina.

El nivel 2.4 de la unidad intermedia cuenta con el repertorio lítico más abundante de la serie analizada en la presente excavación, con un total de 981 piezas. Se recuperó un conjunto importante de hasta 134 núcleos (7 fragmentos y 3 nódulos naturales con alguna extracción). Además, se contabilizaron 153 restos de talla, producidos en el proceso de talla de los nódulos de sílex naturales incorporados a los depósitos fluviales estudiados. El grupo más representado es, sin duda, el de los productos de lascado, con 664 lascas: 238 lascas simples, 116 fragmentos de lasca simple, 20 lascas de primer orden y 220 


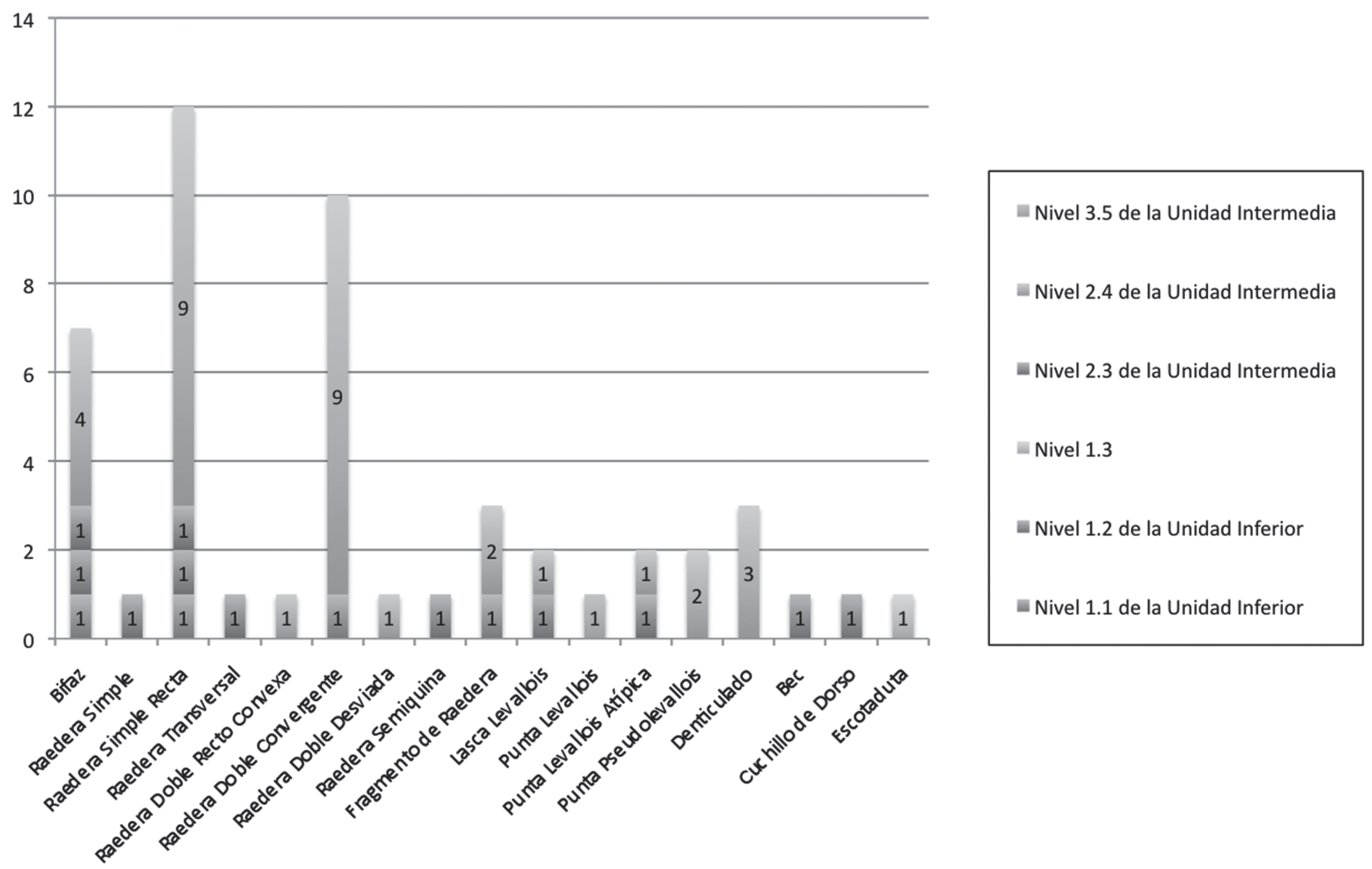

Fig. 10.-Clasificación tipológica de los útiles documentados en el yacimiento arqueológico del 12 de Octubre excavado en el año 2005 (valores absolutos).

lascas y fragmentos de lasca de segundo orden, 38 lascas laminares y fragmentos de lascas laminares, 28 lasquitas y fragmentos de lasquitas y una lámina. Entre los útiles destaca la presencia de 4 bifaces (uno es un fragmento), una lasca levallois, una punta levallois, una punta levallois atípica, 2 puntas pseudolevallois, 3 denticulados y 16 raederas ( 9 raederas simples rectas, 1 doble desviada, 3 dobles convergentes, 1 doble recto-convexa y 2 fragmentos de raedera).

Finalmente, en el techo de la secuencia fluvial analizada, correspondiente al nivel 3.5 de la unidad superior, se ha documentado un escaso conjunto lítico compuesto por 30 piezas, con una mayoría de productos de lascado (20), siendo en su totalidad lascas simples, si bien dos de ellas son fragmentos y dos lascas simples con tendencia laminar. Los núcleos son escasos, así como los restos de talla. Solamente existe una pieza con categoría de útil, se trata de una punta levallois.

Desde un punto de vista tecnológico se enumeran de forma hipotética las cadenas operativas líticas del yacimiento según los diferentes niveles estratigráficos, debido a que la propia dinámica fluvial indica claramente que las cadenas operativas están incompletas, sólo representadas por algunas de las categorías morfotécnicas. Por tanto, los esquemas operativos reconocidos a partir del material quedan expuestos simplemente a nivel de hipótesis, dada la complejidad de la agrupación y el sesgo generado por el transporte fluvial. Se ha realizado una aproximación cualitativa a los esquemas de talla sobre una muestra suficientemente representativa capaz de ofrecer información tecnológica significativa (fig. 11):

1. Esquema operativo de explotación trifacialortogonal documentado en series de materiales afectados por pátina fluvial en el nivel 2.4 de la unidad intermedia.

2. Esquemas operativos de configuración bifacial a partir de bloque y sobre lasca en el nivel 2.4 de la unidad intermedia. Un ejemplo de este esquema queda reflejado en la figura 12(8): un bifaz configurado sobre lasca ( $1^{\text {a }}$ serie: cara ventral) que presenta 

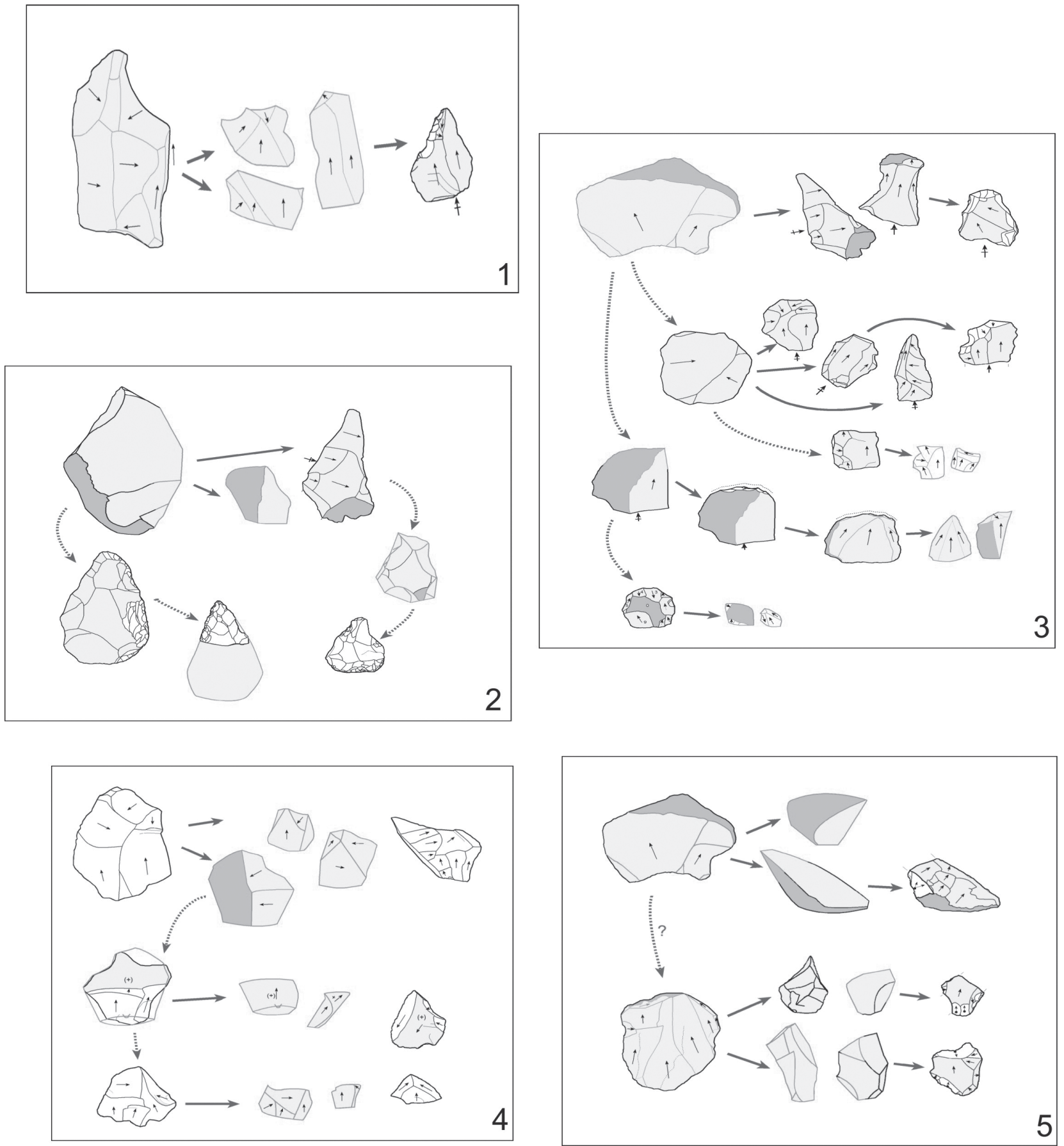

Fig. 11.-Reconstrucción hipotética de cadenas operativas existentes en el conjunto lítico del 12 de Octubre.

múltiples áreas con retoque diversificado, aproximándose a la noción de bifaz-soporte de útil definida por Boëda (1997).

3. Esquemas operativos de explotación con fase de configuración inicial de bloque, ampliamente documentada, plena producción (de tipo levallois recurrente centrípeto), y reexplotación (esquema levallois ortogonal). Así mismo se documenta algún esquema de explotación sobre lasca, u ocasionalmente sobre útil reciclado (levallois unipo- 
lar lineal). La producción lítica documentada en este nivel de gravas se caracteriza por una elevada proporción de esquemas operativos de concepción levallois. La figura 12 (1-7) presenta los esquemas diacríticos levallois más característicos de la serie documentada en el nivel 2.4 de la unidad intermedia.

4. Esquemas operativos levallois sobre canto o bloque y esquema sobre lasca, en el que se explota principalmente la cara inferior (ventral) de la lascasoporte. Si bien el inicio puede constar de unas pocas extracciones, proporcionando series de tipo kombewa (lascas y puntas), las explotaciones más intensas pueden acabar borrando cualquier huella de la cara ventral de la lasca-soporte. Son esquemas operativos documentados en el nivel 2.3 de la unidad intermedia.

5. Esquemas operativos de explotación de pocas extracciones en series alternas pueden suponer tanto esquemas independientes para la creación de soportes espesos como el inicio de explotación de núcleos levallois; además el método recurrente centrípeto y otro recurrente unipolar con producción de soportes alargados (láminas levallois). Estos esquemas operativos se detectan tan solo en la unidad inferior y por tanto son los más antiguos.

En conjunto, la industria paleolítica de este yacimiento se caracteriza por estar tallada en su práctica totalidad en sílex, dirigida a la producción de lascas, tanto mediante débitage levallois, discoide, multidireccional y unidireccional, predominando por tanto los productos de lascado, frente al escaso número de núcleos. Por otro lado es de destacar la presencia de útiles retocados, aunque en un porcentaje bajo, así como un porcentaje mínimo de macroutillaje típicamente achelense (bifaces). El escaso número de macroutillaje achelense, en su mayor parte rodado, así como el predominio de productos de lascado, algunos siguiendo modelos de talla levallois, permite atribuir este yacimiento al musteriense. Como se ha indicado con anterioridad, el presente conjunto proporciona material relacionado con una producción levallois en el sentido en que ha sido definido por Boëda (1991), tanto levallois recurrente centrípeto como levallois unipolar, tanto sobre lasca como sobre bloque. El material retocado y configurado también apunta a una atribución musteriense. Los bifaces o fragmentos de éstos son escasos (6) sobre una amplia colección en la que predominan las lascas y útiles sobre lasca, fundamentalmente raederas dobles y denticulados. Los bifaces presentes son de pequeño formato, muy probablemente sobre lasca y con retoque final diversificado sobre distintos segmentos, lo que los aproxima a la noción de bifaz-soporte de útil definida por Boëda (1997). Este tipo de bifaces, al igual que los aplanados, y bien configurados con percutor blando (de los cuales se encuentra un ejemplar con la parte proximal fracturada) se pueden relacionar más frecuentemente con industrias musterienses de los estadios isotópicos OIS 4 y 3 (Soressi, 2002).

\section{Yacimiento de Villaverde-Barrio de Butarque}

\section{Situación geomorfológica y secuencia sedimentaria}

Con motivo de los hallazgos arqueológicos y paleontológicos efectuados en la fase de los movimientos de tierra del vial 11 del proyecto de urbanización de Villaverde-Barrio de Butarque, se realizó una excavación sistemática en los meses de febrero y marzo de 2006. Ésta se planteó en tres sectores, que tras un rebaje superficial del terreno fueron excavados manualmente por niveles estratigráficos.

Las excavaciones se situan inmediatamente aguas abajo (sur) de la confluencia del arroyo Butarque (fig. 1). Este hecho determina que los depósitos fluviales presenten aquí unas características, sobre todo litológicas (en los tamaños grava y arena fundamentalmente) de tipo mixto, con influencia más o menos importante del arroyo Butarque, que incorpora los materiales neógenos existentes en su cuenca de drenaje.

De los datos procedentes de los tres sectores excavados en este yacimiento se ha interpretado la existencia de tres unidades fluviales principales (inferior, intermedia y superior) superpuestas que se encuentran en contacto erosivo sobre el sustrato neógeno. Cada una de estas tres unidades se encuentra constituida por dos niveles estratigráficos (fig. 8B). La serie culmina con una unidad de aportes laterales (tipo glacis), de hasta $2 \mathrm{~m}$ de potencia, que fosiliza discordantemente todo el conjunto. La potencia total de los depósitos (fluviales y tipo glacis) excavados prácticamente alcanza los 9 metros (Silva et al., 2008).

La unidad inferior corresponde a los depósitos de terraza más antiguos y se situan discordantemente sobre el sustrato neógeno, presentando una 

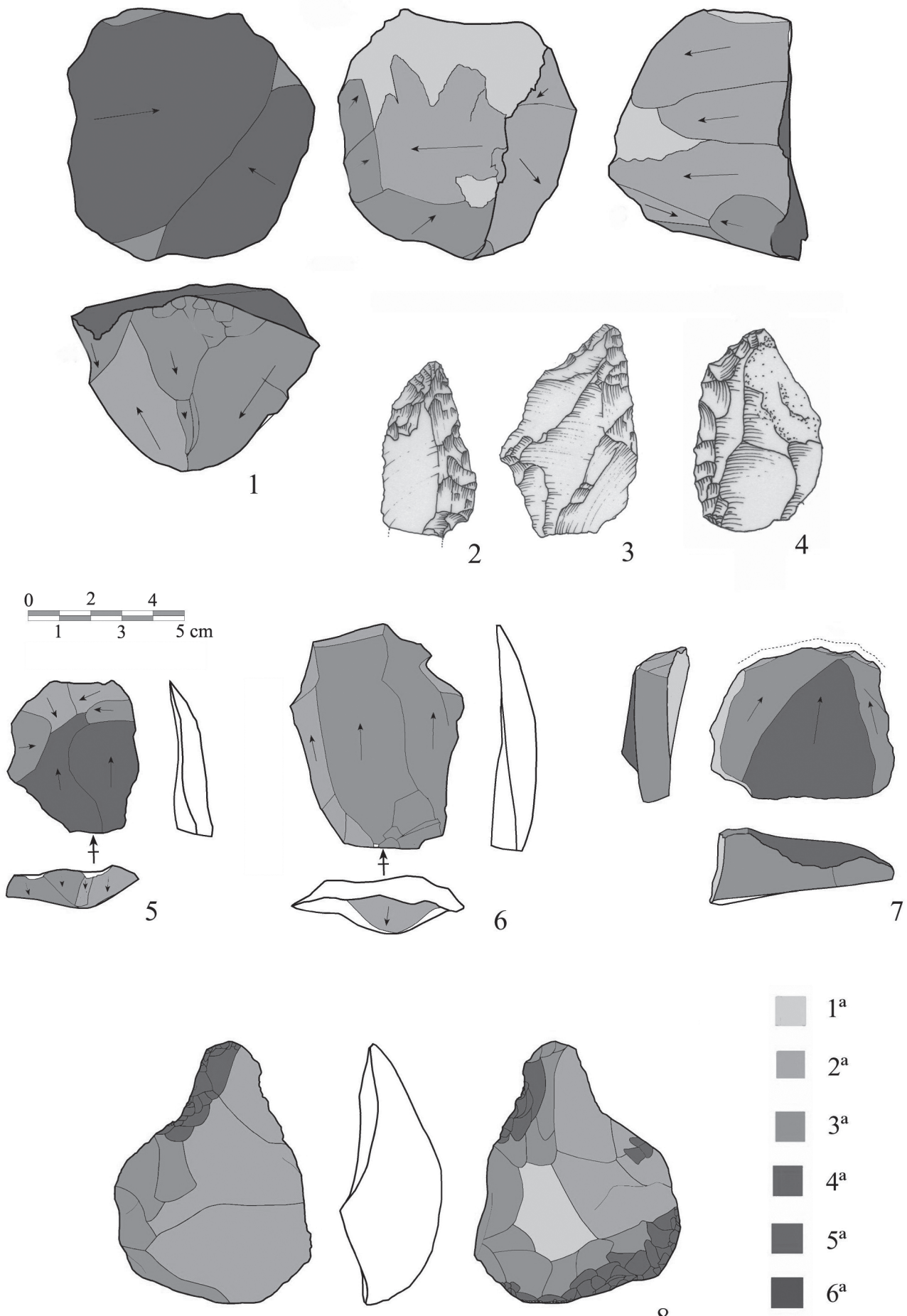

Fig. 12.-Esquemas diacríticos del conjunto lítico del 12 de Octubre (orden de las series según escala cromática adyacente): 1) esquema diacrítico de núcleo levallois recurrente centrípeto en fase de plena producción sobre bloque; 2 y 3 ) raederas dobles convergentes sobre soportes levallois; 4) denticulado sobre lasca cortical; 5 y 6 ) lascas levallois obtenidas a partir de superficie levallois de acondicionamiento centrípeto (5) y unipolar (6); 7) núcleo unipolar convergente para producción de puntas, explotado con método lineal; éste se elabora a partir de un raspador denticulado sobre lasca espesa reciclado en su cara dorsal (productos levallois) obtenidos desde una truncadura proximal (acondicionamientos de plataforma); 8) bifaz configurado sobre lasca ( $1^{\mathrm{a}}$ serie: cara ventral) que presenta múltiples áreas con retoque diversificado, aproximándose a la noción de bifaz-soporte de útil definida por Boëda (1997). 
potencia máxima vista de hasta 3,25 metros (fig. 8B). Está compuesta por dos niveles estratigráficos de carácter granodecreciente culminados por limos y arcillas de llanura de inundación, con desarrollo de paleosuelos a techo. Todas son de carácter arenoso (medio a grueso) con una importante cantidad de gravas, que pueden alcanzar diámetros de hasta $5 \mathrm{~cm}$. Las unidades intermedia y superior (más modernas) se encuentran superpuestas a la descrita anteriormente y están constituidas por depósitos mayoritariamente arenosos en los que se advierte claramente la influencia de los aportes laterales procedentes de la cuenca de drenaje del arroyo Butarque (cantos de caliza y sílex), especialmente en la unidad superior. El techo de la unidad intermedia se encuentra afectado por numerosas microfallas de salto decimétrico, cuya actividad da lugar a la generación de niveles de deformaciones sinsedimentarias por licuefacción en la base de la unidad superior (Silva et al., 2008).

\section{Descripción y características tecnológicas de la industria lítica}

Durante la intervención arqueológica se documentó un conjunto con un número representativo de 1.308 piezas líticas en los diferentes niveles estratigráficos diferenciados, así como diversos restos de fauna pleistocena. La práctica totalidad de las piezas líticas recuperadas aparecieron a techo de la unidad inferior (nivel 1.2), con 1.130 piezas, siendo muy escaso el material lítico tallado recuperado en las restantes unidades, en relación al enorme volumen de terreno excavado y al elevado número de fragmentos y nódulos naturales de sílex transportados por acción fluvial.

En una primera valoración de los conjuntos líticos ha de resaltarse que la mayoría de las piezas líticas recuperadas en las unidades intermedia y superior aparecen asociadas a sus niveles de arenas y gravas basales, especialmente en sus contactos discordantes con las arcillas neógenas en los tres sectores excavados. No obstante, es a techo de la unidad inferior donde se recuperó la práctica totalidad de las piezas líticas analizadas, asociadas a facies arenosas de una barra interna de meandro y mostrando diferentes grados de rodamiento (Silva et al., 2008).

El análisis estratigráfico indica que el yacimiento englobaría dos secuencias fluviales solapadas (parcialmente superpuestas) en contacto discordante sobre el sustrato neógeno (Silva et al., 2008). Las unidades inferior e intermedia, presumiblemente las más antiguas (fig. 8B), corresponderían a los niveles superiores $\mathrm{Mz}_{5}$ y quizá representando la unidad inferior el techo de $\mathrm{Mz}_{4}$ de la TCMZ. Por el contrario la unidad superior, con significativos aportes mixtos procedentes del Butarque ya se correlacionaría con los niveles de tipo Mx correspondientes al Pleistoceno superior (Silva et al., 2008).

El conjunto lítico correspondiente al techo de la unidad inferior (1.130 piezas) y a la base de la unidad intermedia (162 piezas) es el más abundante, con un total de 1.292 piezas líticas, siendo un conjunto localizado claramente en posición secundaria ya que alrededor del $76 \%$ de la industria presenta diferentes grados de rodamiento. Prácticamente toda la industria se encuentra tallada en sílex, existiendo solamente dos piezas elaboradas en cuarcita, claramente procedentes de otros sistemas fluviales de la región. Existe un empleo masivo de variedades grisáceas de sílex, debido a que es la que más abunda de forma natural en los depósitos fluviales, pero también hay una selección marcada de otras variedades como el sílex translúcido y el melado, que son muy poco frecuentes en estos depósitos y posiblemente fueron transportadas allí para su talla. Más del $50 \%$ de la muestra no presenta alteraciones visibles, pero el resto presenta frecuentemente claros rasgos de desilicificación o deshidratación postdeposicional. En menor medida también aparecen otras alteraciones propias de estos medios fluviales como son las carbonataciones, presencia de óxidos de hierro y manganeso, así como pátinas hídricas.

Con respecto a las categorías morfotécnicas presentes, el $60 \%$ de la muestra aproximadamente son fragmentos de lasca, el $8 \%$ núcleos, otro $8 \%$ útiles y un $22 \%$ lascas, existiendo sólo dos elementos de macroutilllaje: un bifaz y una pieza con explotación/configuración triédrica (fig. 13 -1-). Por otro lado, las lascas presentan en su mayoría pocas extracciones previas en el anverso (generalmente no más de 4), siendo preferentemente direcciones centrípetas. Tecnológicamente los talones de las lascas son en un $60 \%$ de los casos lisos, diedros en un $14 \%$ y facetados en el $4 \%$. El porcentaje de débitage levallois es muy bajo (varias lascas y una punta). En cuanto al retoque, predominan los retoques abruptos, formando ángulos superiores a $45^{\circ}$, denticulados y directos, es decir, sobre la cara dorsal de la pieza.

En el conjunto lítico situado en el techo de la unidad inferior (nivel 1.2) se detectan distintos siste- 

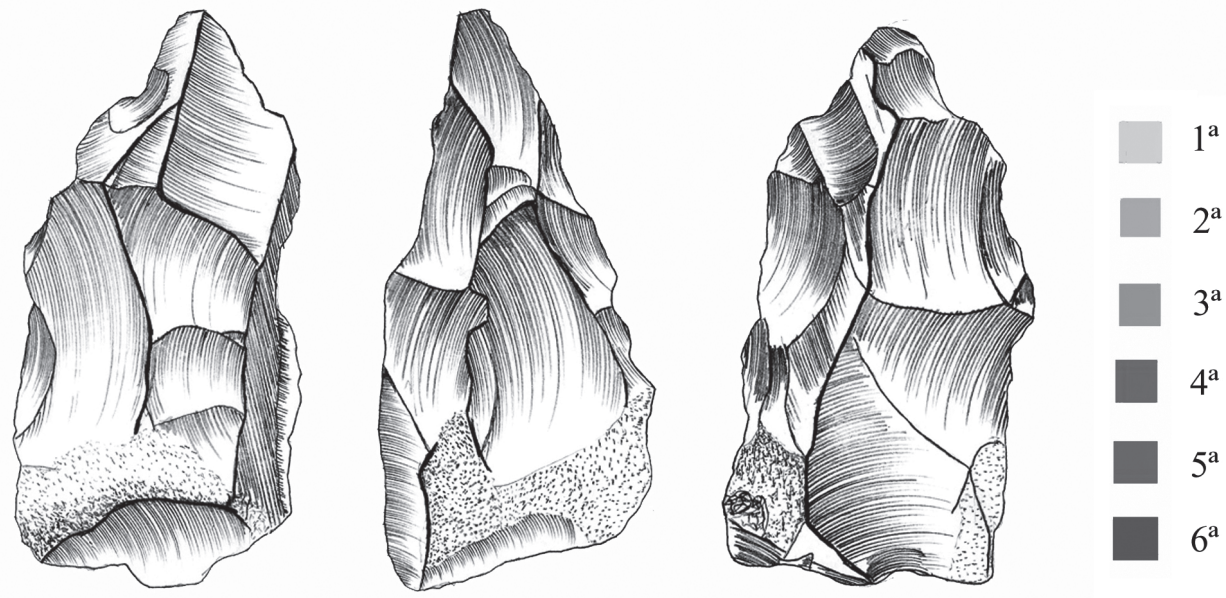

1
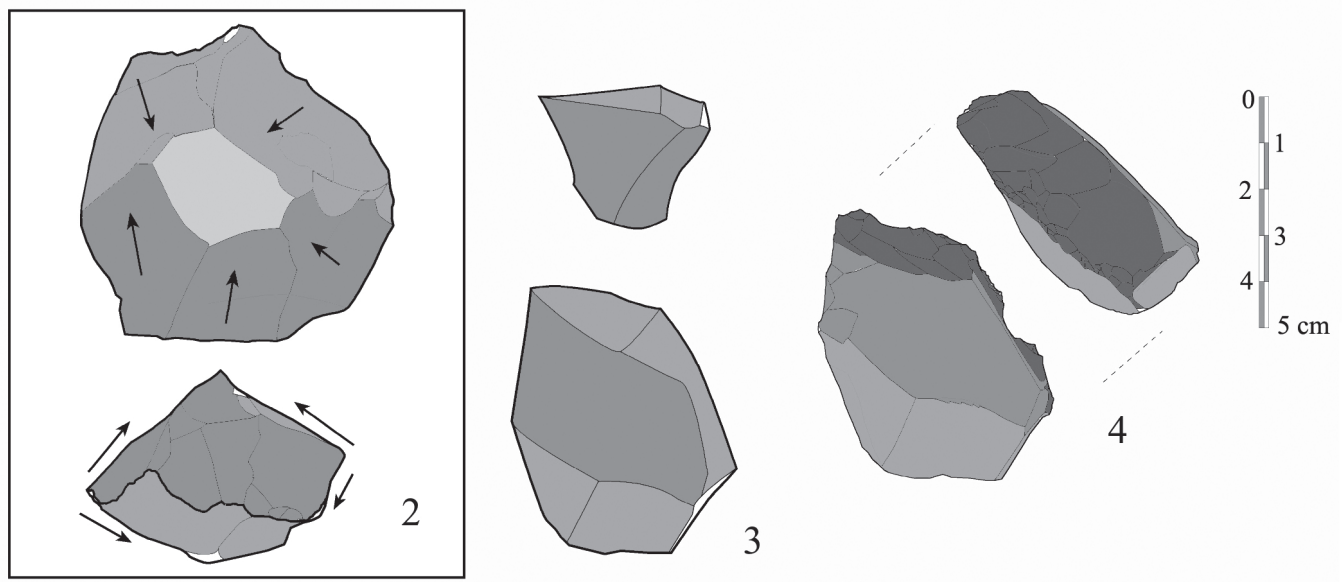

3
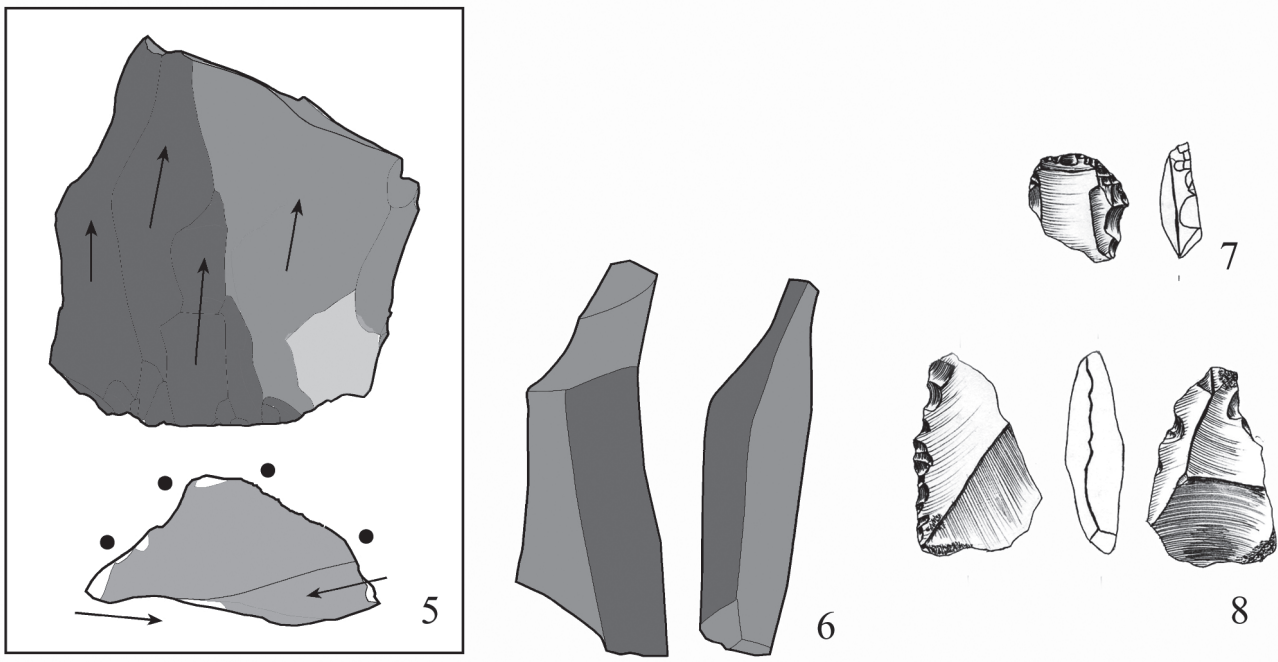

8

Fig. 13.-Esquemas diacríticos y piezas líticas de Villaverde-Butarque (orden de las series según escala cromática adyacente): 1) pieza con explotación/configuración triédrica; 2) núcleo discoide sensu lato (Slimak) explotado mediante series unipolares convergentes independientes de alternancia discontínua; 3) producto generado por una explotación discoide sensu lato; 4) denticulado sobreelevado; 5) núcleo de explotación unipolar; 6) productos generados por una explotación unipolar (reconstrucción ideal a partir del patrón de negativos del núcleo $n^{\circ} 5$ de la imagen); 7) raspador subcircular; 8) denticulado sobre núcleo de pequeño formato. 


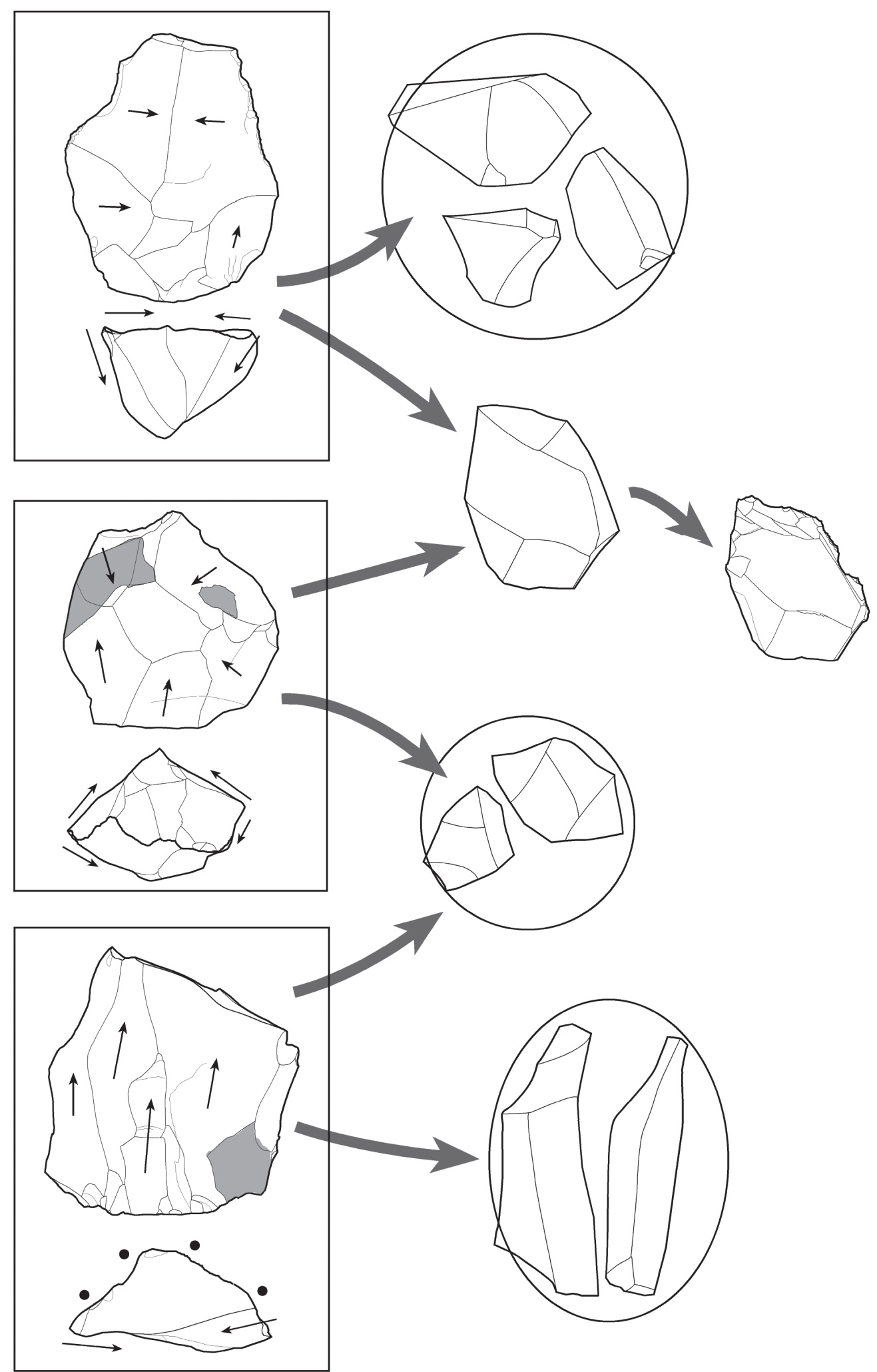

Fig. 14.- Síntesis de los tres principales esquemas de explotación en el yacimiento de Villaverde-Butarque. De arriba a abajo: talla trifacial, débitage discoide y débitage laminar. El utillaje retocado se realiza principalmente sobre lascas espesas obtenidas de talla trifacial o débitage discoide. 
mas de débitage, como son los modos de reducción unifaciales, simples y abruptos, bifaciales, preferentemente discoides (fig. 13 -2,3-), en menor medida levallois y laminar. Los tres principales esquemas de explotación son la talla trifacial, el débitage discoide y el débitage laminar (fig. 14). Además debe anotarse la presencia muy reducida también de macroutillaje más propio de una tecnología achelense (bifaces, triedros -fig. 13(1)- y hendedores). Existe gran diversidad del material retocado, principalmente sobre lascas espesas obtenidas de talla trifacial o débitage discoide (fig. 14), destacando la presencia de raederas, denticulados y raspadores (fig. $13-4,7,8-$ ) y existiendo un utillaje levallois con una baja frecuencia (lascas y puntas) y una baja frecuencia de raederas, en algunos casos de tipo Quina.

El yacimiento más moderno se situa en la base de la unidad superior (nivel 3.1). La industria recuperada en él se compone de 95 piezas líticas, localizadas en los niveles de gravas basales de este nivel estratigráfico, siendo también un conjunto contextualizado en posición secundaria (alrededor del 85\% de las piezas presenta un grado de rodamiento acentuado). También se encuentra tallada fundamentalmente en sílex, estando la cuarcita prácticamente ausente salvo por la aparición de una lasca simple elaborada en este material. Prácticamente todas las piezas son variedades de sílex grisáceo, siendo marginales otros tipos de sílex. El 36\% de las piezas no presenta alteraciones visibles, pero el porcentaje restante presenta frecuentemente procesos superficiales de desilicificación y deshidratación postdeposicional. Con respecto a la composición del conjunto lítico, el $47 \%$ de la muestra se compone de fragmentos de lasca, el $11 \%$ de núcleos, el $14 \%$ de útiles y un $27 \%$ de lascas, existiendo sólo un bifaz de pequeño tamaño. El porcentaje de industria levallois también es muy bajo (3 lascas). Por su parte, las lascas suelen presentar pocas extracciones previas en el anverso (1-3), siendo preferentemente direcciones unipolares. Tecnológicamente los talones de las lascas son en su mayoría lisos (en un $52 \%$ de los casos), diedros en un $21 \%$ y poliedros en $6 \%$, siendo el retoque predominantemente abrupto y directo.

En el material lítico de Villaverde-Butarque se hallan explotaciones de tipo unipolar en volumen con percutor de piedra (fig. 13 -5 y 6-) y útiles de pequeño formato (ej. raspador fig. 13 -7-) que bien podrían adscribirse a momentos antiguos (OIS 5) en los que existen industrias de este tipo en el noroeste de Europa (Révillion, 1995), si bien en la Península ibérica no existen ejemplos por el momento. La mayor parte de los núcleos presentan explotaciones de tipo unipolar lateral abrupto o de tipo discoide sensu lato (Peresani, 2003). Ambas son poco diagnósticas a nivel cronológico dado su amplia extensión en el tiempo. Existen algunas piezas tipo triedro sobre pequeños bloques de sílex que podrían pertenecer a esquemas de talla trifacial en los que parece haber una mayor vocación de explotación que de configuración. Este tipo de esquemas han sido descritos en contextos de Pleistoceno medio final en yacimientos clasificados dentro del Achelense meridional por Bordes (Boëda, Geneste y Meignen, 1990; Boëda, 1991; Chevrier, 2006) o en el caso del nivel IV de la Cova de Bolomor (Cuartero, 2004). No obstante también ciertas industrias de Paleolítico superior presentan esquemas de producción parecidos, denominados en este caso producciones à éclats courts normalisés, para la producción de soportes de raclettes durante el Badeguliense (Fourloubey, 1996; Morala, 1995). Del mismo modo, existen útiles sobreelevados así como útiles sobre núcleos agotados documentados en algún caso. De este modo, dada la mala documentación que tenemos de explotaciones de este tipo para momentos más recientes, no se puede descartar su adscripción al Pleistoceno superior, ya que las explotaciones unipolares en volumen con piedra son igualmente frecuentes en industrias del Paleolítico reciente (Pelegrin, 2000).

\section{Contextualización geomorfológica de los yacimientos paleolíticos analizados}

Con el fin de poder contextualizar geomorfológicamente los yacimientos paleolíticos analizados en relación a los diferentes niveles de terraza del Manzanares y a otros yacimientos relevantes excavados durante el siglo XX, se hace necesario analizar el conjunto de terrazas del valle del Manzanares.

La figura 15 muestra un esquema sintético preliminar de los perfiles longitudinales de las terrazas del Manzanares desde el "Embalse de El Pardo" hasta su desembocadura en el Jarama, aguas abajo de Rivas-Vaciamadrid, elaborado a partir de un modelo digital del terreno. El perfil longitudinal abarca un tramo de algo más de $42 \mathrm{~km}$ medidos a lo largo del cauce actual del río, sobre el que se han proyectado las altitudes de todos los niveles de terraza del Manzanares representados en las carto- 


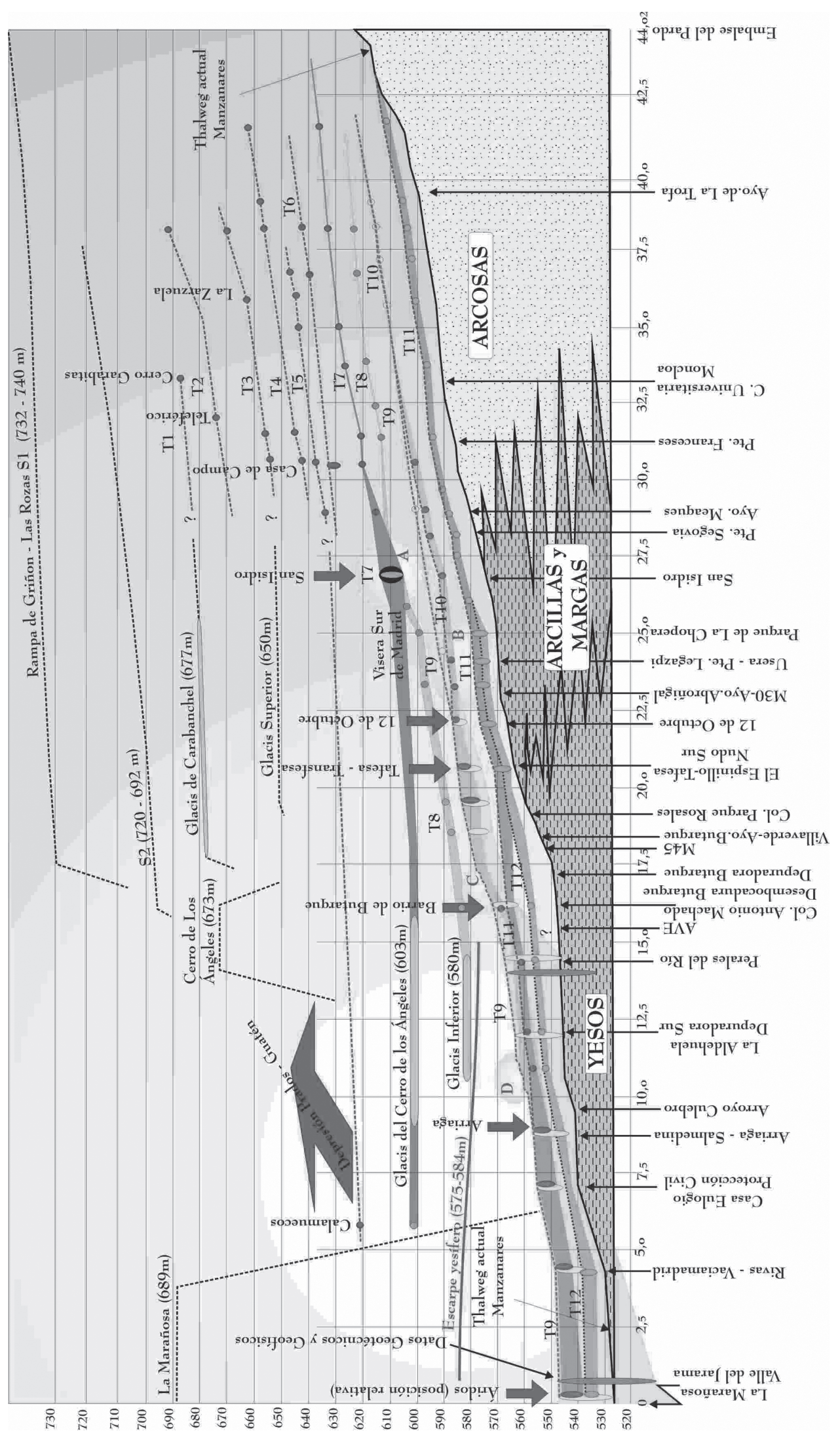

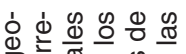

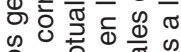

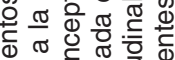

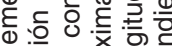

ब赵

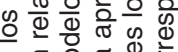

응 둥은 은

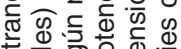

잉

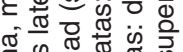

은

क స

은 응 80

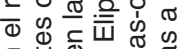

ब

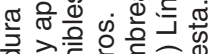

व.

O.

ह흥 m

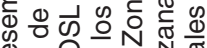

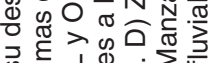

कि

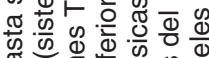

ष

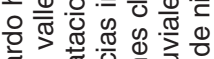

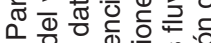

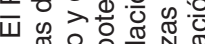

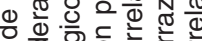

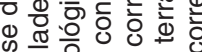

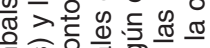

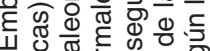

ब.

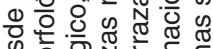

ه

\%

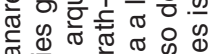

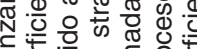

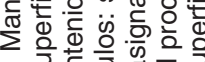

ब

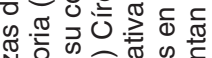

N

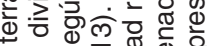

(⿻)

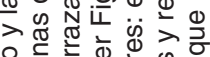

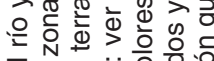

용 \&

\&

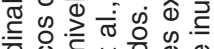

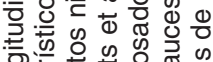

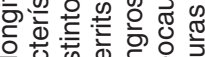

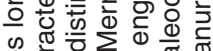

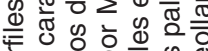

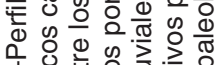

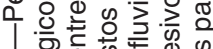

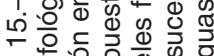

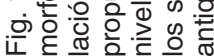


grafías existentes (Silva, 1988; Goy et al., 1989; Silva \& González Hernández, e.p.) así como datos puntuales procedentes de otros trabajos de síntesis (Silva et al., 2003; Bárez \& Pérez-González, 2006). Los datos altimétricos se han implementado en un MDT de la zona a escala 1:10.000 y se han proyectado sobre el cauce del río. En la figura 15 también se han incluido los perfiles longitudinales de las superficies pre-encajamiento (rampas areno-feldespáticas plio-pleistocenas) y sistemas de glacis de vertiente encajadas en ellas, así como las superficies de los elementos fisiográficos más relevantes en el área analizada, como la "Visera Sur de Madrid", escarpes en yesos del valle inferior, el relieve de "La Marañosa", el "Cerro de los Ángeles" y la Depresión Prados-Guatén (antiguo curso del Manzanares, Silva et al., 1988a).

La contextualización geomorfológica de los yacimientos debe de olvidar las clásicas correlaciones altimétricas (típicamente lineales), como las que hemos venido exponiendo en este trabajo, ya que lo realmente informativo es referir los yacimientos a superficies geomorfológicas con significado cronológico, es decir a las isocronas delineadas por las antiguas superficies de las sucesivas llanuras de inundación que se han ido sucediendo a lo largo del tiempo. Este tipo de correlaciones se viene aplicando con excelentes resultados desde mediados de los años 90 en el análisis de valles fluviales de la fachada pacífica de los EEUU (Merrits et al., 1994; Wholl et al., 2001; fig. 16) y que en la Península Ibérica solo se han aplicado a algunos sistemas fluviales como el río Mula (Silva et al., 1995), el río Gállego (Benito et al., 1998, Sancho et al., 2005) y el río Huerva (Guerrero et al., 2008), todos los cuales muestran evidentes signos de engrosamiento por subsidencia evaporítica (Gállego y Huerva) o deformaciones neotectónicas (Mula). Su combinación con dataciones isotópicas, y más recientemente TL y OSL, aportan datos fundamentales para la identificación y comprensión de las mencionadas superficies fluviales isocronas dentro del análisis de niveles de terrazas. En el presente estudio se introduce una variable más, que es la potencia (valores mínimos observados) de los niveles fluviales implementados en el modelo. Los círculos indican strathterraces normales con espesores que no sobrepasan los 2-3 metros de potencia, como es el caso de la mayor parte de los niveles fluviales del Manzanares aguas arriba de la terraza de San Isidro (fig. 15). Las elipses prolatas indican la potencia en metros de los niveles fluviales engrosados correspondien- tes. Los colores de círculos y elipses únicamente indican la edad relativa asignada a las terrazas por las correlaciones clásicas antiguas. Los datos importantes en la figura 15 son las zonas sombreadas que representan la potencia y morfología longitudinal de los paleovalles excavados y rellenados (cut \& fill) correspondientes a las distintas líneas isocronas fluviales inferidas en este estudio, así como las líneas gruesas a trazos (colores) que representan la probable geometría de superficies isocronas correspondientes a los distintos paleo-niveles de llanura de inundación que responderían a niveles de terraza isócronos verdaderos. En este gráfico no se han implementado las dataciones TL y OSL existentes para el Manzanares ya que, aunque significativas, son todavía escasas y por tanto las superficies isocronas propuestas tienen un valor cronológico tan solo relativo.

Los datos más significativos respecto a este estudio que arroja el gráfico de correlación de la figura 15, son los siguientes:

1. El valle del Manzanares presenta 12 niveles fluviales (T1-T11), contando con el de la llanura de inundación actual a +2,5-3 m (T-12), que no se ha representado en el gráfico. No obstante se observa que la extensión de los diferentes niveles fluviales es discontinua mostrando distintas zonas de "arranque" a partir de la entrada del valle en los materiales arcillosos y margosos del relleno neógeno de la Cuenca de Madrid, y muy especialmente a su entrada en los materiales yesíferos de centro de cuenca. En la mayor parte de los casos estas zonas de arranque están en relación con la existencia de antiguos escalones de erosión remontante.

2. Las terrazas superiores (T1 a T6) muestran un dispositivo de encajamiento clásico y se pueden correlacionar con las superficies de los distintos sistemas de glacis existentes en el valle inferior del Manzanares. Sólo se registran de manera continua en la zona superior del valle sobre las arcosas de borde de la cuenca, donde prácticamente no existe registro lítico asociado a ellas.

3. La "Terraza de San Isidro" corresponde a la terraza T7 (A en fig. 15) y representa, junto con la T8, los niveles de terraza con industria lítica más antigua del valle del Manzanares (achelense). Se observa que estos dos niveles ya muestran procesos de engrosamiento y marcan el inicio de la incisión directa del valle sobre las facies de arcillas y margas intermedias de la cuenca. Se pueden correlacionar con un alto grado de fiabilidad con los niveles de glacis de vertiente del Cerro de los Ángeles - 


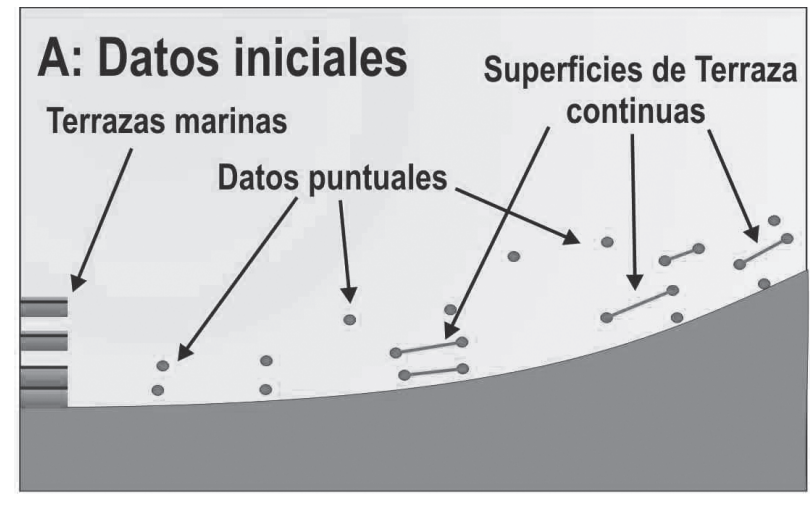

\section{B: Correlación inicial}

Los niveles de terraza fluviales no tienen porqué correlacionarse altimétricamente con los niveles marinos ni entre ellos mismos aunque presenten la misma altimetría.

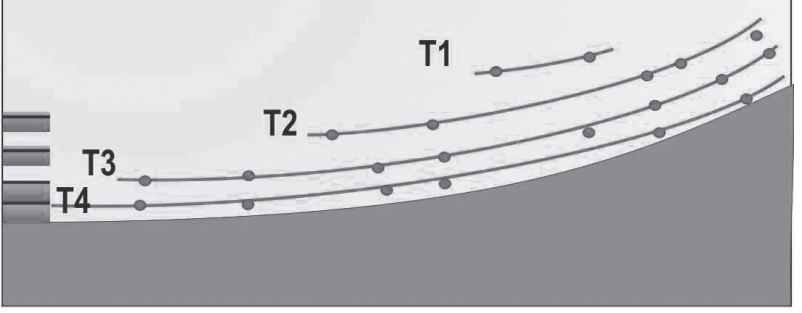

\section{C: Adquisición de nuevos datos}

Nuevos datos adquiridos por foto aérea y campañas de campo

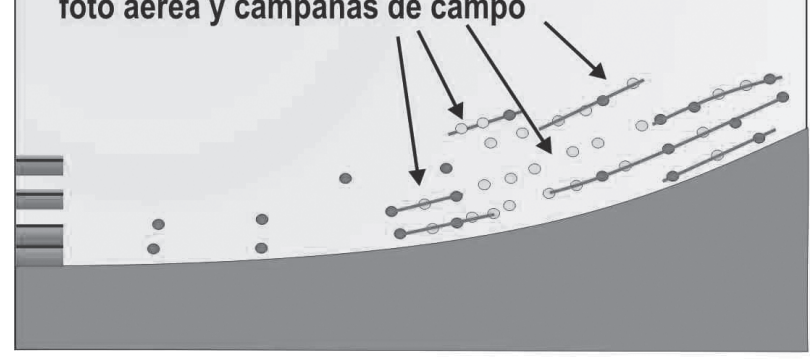

\section{D: Correlación revisada}
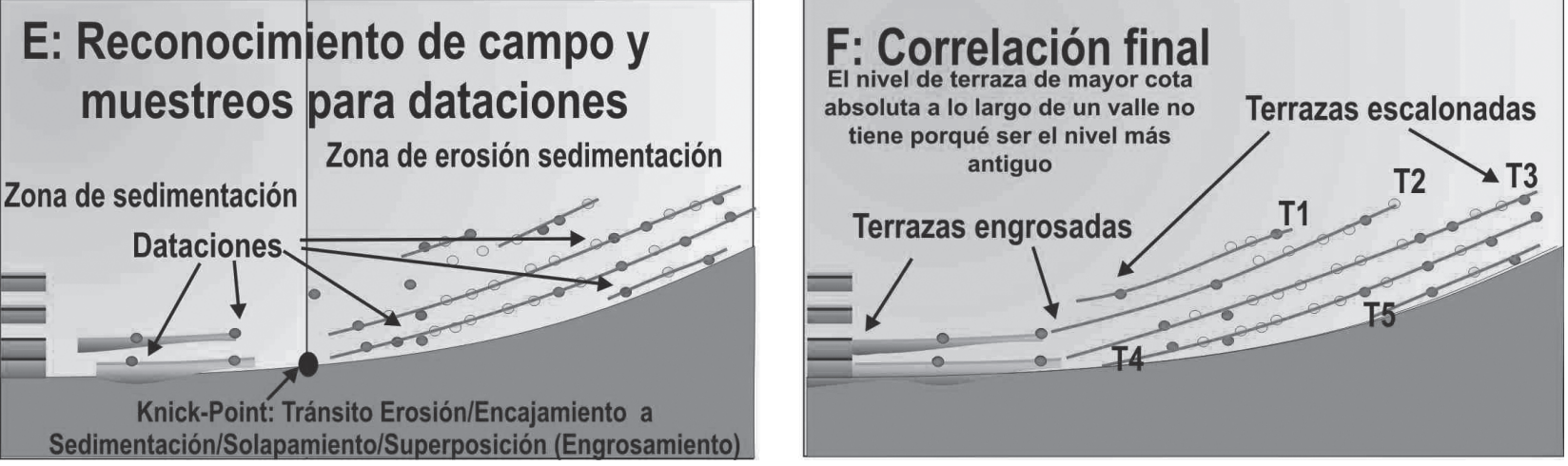

Fig. 16.-Esquema metodológico propuesto para la correlación longitudinal de niveles fluviales siguiendo criterios geomorfológicos modernos en función de datos cronológicos relativos (fauna, industria) y numéricos (dataciones) existentes para la zona costera pacífica de los EEUU (Modificado de Merrits et al., 1994). En nuestro caso los niveles marinos (inexistentes) representarían los diferentes niveles fluviales relacionados con las terrazas del río Jarama del que es tributario el Manzanares.

Visera Sur de Madrid y glacis inferior del valle Inferior del Manzanares (fig. 1).

4. La Terraza Compleja del Manzanares (TCMZ) se asocia a los niveles de terraza T9 y T10, y marca el comienzo de la incisión directa del río sobre los materiales evaporíticos neógenos. La T9 se puede asociar a las unidades $\mathrm{Mz}_{1}, \mathrm{Mz}_{2}$ y $\mathrm{Mz}_{3}$ de Silva (2003), a la que se solapa o yuxtapone (según secto- res) la T10 que correspondería a las unidades $\mathrm{Mz}_{4}$ y $\mathrm{Mz}_{5}$ del mismo autor. La T9 también se asocia con la instalación de los arroyos Butarque y Culebro, y se han representado los escalonamientos en offlap (niveles Mx -no a escala) asociados a sus desembocaduras coincidentes con escalones de erosión remontante significativos (C y D en fig. 15). Ambos niveles son los más problemáticos del Manzanares 
ya que son los que registran los yacimientos pertenecientes al Pleistoceno medio y superior atribuidos tradicionalmente a un único nivel de terraza. En estos niveles se localizan los yacimientos analizados en este estudio así como los más significativos del valle inferior del Manzanares (i.e. Arriaga, Perales del Río, Culebro). El espectacular engrosamiento de los niveles solapados, superpuestos y/o yuxtapuestos (según sectores) de estos dos niveles de terraza coinciden espacialmente, y seguramente también temporalmente con la generación de los escarpes yesíferos de más de 60 metros de altura que actualmente enmarcan los valles del Manzanares y Jarama en el sector analizado.

5. Los niveles inferiores T11 y T12 son los que libran industria de Paleolítico medio, y corresponden con los descritos por Obermaier (1925). Se ha señalado como zona B en la figura 15 , ilustrando similares procesos de redigestión y resedimentación a los de la TCMZ. Toda la industria del Paleolítico inferior que aparece en estos niveles de terraza es resedimentada, o reutilizada. En algunos sectores en el techo de dichos niveles incluso contienen excepcionalmente conjuntos de Paleolítico superior, como las piezas solutrenses del yacimiento de El Sotillo (Martínez de Merlo, 1984). Por otro lado hay que advertir que a techo de los niveles T9 y T10, que componen la TCMZ, es posible también encontrar yacimientos del Paleolítico medio, bien en superficie o bien fosilizados por los aportes laterales (abanicos y derrames) que continuaron siendo activos, hecho que es muy común aguas abajo de la confluencia del Culebro.

6. La "correlación altimétrica directa" como se ha venido haciendo hasta la fecha, no es fiable ya que existen importantes escalones de erosión remontante a partir de la zona de "San Isidro", y especialmente en el entorno del Butarque-Tafesa que las invalidan. Estos escalones indujeron importantes fenómenos de redigestión y resedimentación fluvial aguas abajo de "San Isidro". En todos los casos estos escalonamientos del perfil longitudinal del río se encuentran relacionados con los tránsitos facies de borde-intermedias e intermedias-centrales de la antigua cuenca neógena, por lo que la componente lito-estructural es relevante en la evolución geomorfológica del área de estudio.

7. A partir de la TCMZ (T9+T10) se observa que todos los niveles fluviales arrancan aguas arriba con escalones de erosión remontante menores y que existe un engrosamiento progresivo hasta su culminación en el valle inferior del Manzanares. Este hecho indica, como apuntan Merrit et al. (1994) la generación de caídas de niveles de base locales, que en este caso estarían relacionados con fenómenos de subsidencia kárstica a partir de la zona de la desembocadura del Butarque y el actual Nudo-Sur. Estas caídas o pulsos negativos provocarían la sedimentación masiva aguas abajo de los mismos. Aguas arriba se propagarían dando lugar a importantes procesos de erosión de los propios depósitos fluviales que provocarían importantes fenómenos de redigestión interna del valle.

Otros datos que pueden extraerse del gráfico de la figura 15 es que el desarrollo de los relieves del "Cerro de los Ángeles" y "La Marañosa" serían enteramente cuaternarios, posteriores a la formación del "Glacis de Carabanchel", quizá coetánea al desarrollo del nivel T1. La excavación de dichos relieves estructurales se encuentra relacionada con el desarrollo de los niveles T2 a T6 (Fig. 15) prolongándose probablemente hasta el sector de Calamuecos (T6) donde se encuentran los niveles fluviales más altos del valle inferior del Manzanares descritos por Bárez y Pérez-González (2006). La excavación fluvial de la Depresión Prados-Guatén por parte del antiguo Manzanares también ha de enmarcarse en relación con los niveles fluviales más altos T1 a T5, finalizando en la T6 (Calamuecos), a partir del cual se produciría el proceso de captura fluvial del Manzanares por parte del Jarama propuesto por algunos autores (Riba, 1957, Silva et al., 1988a, Silva et al., 1999).

El último dato relevante es el del perfil de la línea de escarpe principal de los escarpes yesíferos que dominan la margen izquierda del valle inferior del Manzanares, que muestra un neto sentido a contrapendiente respecto a los perfiles longitudinales de terrazas y glacis, además de su geometría abombada. Este dato indica que su origen no tiene porqué estar relacionado únicamente con los procesos de excavación fluvial posteriores a la T6. De estarlo, este marcador geomorfológico habría sufrido un claro proceso de elevación tectónica, dato que estaría de acuerdo con las propuestas neotectónicas y paleosísmicas de algunos autores (Silva et al., 1988a; 1997; Giner et al., 1996; Silva, 2003). Esta línea de escarpe se encuentra definida por el entallado de una pequeña plataforma estructural sobre la que se encajan valles en cuello de botella, alguno de ellos colgado sobre el actual Manzanares (Silva et al., 1988a), pudiéndose considerar un marcador geomorfológico de geometría original similar a la actual. 


\section{Discusión: encuadre cronocultural de los yacimientos analizados}

Los estudios geoarqueológicos (Silva et al., 2008) junto con el análisis tecnológico de los conjuntos líticos procedentes de los yacimientos de Tafesa, 12 de Octubre y Villaverde-Barrio de Butarque presentados en este estudio aportan nuevos datos a la secuencia cronocultural establecida para el valle del Manzanares (Rus, 1987; Baena et al., 2000; Santonja \& Pérez-González, 1997 y 2001; Rubio et al., 2002). En concreto, el presente estudio se encuadra en el área de transición entre el tramo urbano del valle del Manzanares estudiado a principios del siglo XX (i.e. Obermaier, 1925) y su entrada en el sustrato evaporítico donde comienza propiamente dicho el valle inferior del Manzanares, el cual se caracteriza por el desarrollo de la "Terraza Compleja del Manzanares" o TCMZ (Silva, 2003).

La industria lítica de Tafesa se contextualiza en la terraza T9 del Manzanares, de acuerdo a la correlación descrita en el apartado anterior, aunque sus depósitos culminantes registran también los de la T10 que se yuxtapone a ella (fig. 15), como ya se indicó en trabajos anteriores (Silva et al., 2008). El yacimiento posee restos faunísticos atribuidos al Pleistoceno medio, y aunque los conjuntos líticos allí existentes sean cronoculturalmente similares a los conjuntos achelenses localizados en niveles de terraza situados a mayor altura (T7), como son los de San Isidro (Wernert \& Pérez de Barradas, 1925; Santonja, 1976, 1977; Santonja \& Querol, 1980; Gómez Hernanz et al., 2005), Orcasitas (T6), o con otros a menor altura como el de Casa Eulogio (T10) (Quero, 1994), no pueden correlacionarse geomorfológicamente a ellos a no ser que supusiéramos un gran evento de hundimiento o erosión inmediatamente posterior al depósito de la T7 de casi 35 metros de amplitud (fig. 15). A nivel regional, el registro lítico de este yacimiento puede compararse con el de los yacimientos de las terrazas medias del río Tajo situadas a +25-30 m, como Pinedo en Toledo (Santonja, 1976; Querol \& Santonja, 1979) o Cien Fanegas en Aranjuez (Rus et al., 1993; Baena et al., 2010).

En Tafesa, la industria lítica recuperada en la excavación de 1996 se caracteriza por la abundancia de bifaces y triedros dentro de los procesos de façonna$g e$, siendo escasos los hendedores, además de contar con un importante número de productos de lascado, gran parte de los cuales proceden de dicho trabajo bifacial y trifacial de configuración de macroutillaje (figs. 4 y 5). Los núcleos son escasos, evidenciando procesos de talla alternantes parciales y multidireccionales con escasa jerarquización y predeterminación de los productos y nula presencia de débitage levallois (Baena \& Baquedano, 2004; Baena et al., 2010). Estas características tecnológicas corresponden a un conjunto achelense, similar a otros conjuntos de cronología antigua a nivel peninsular. Síntesis recientes indican que el achelense en la Península Ibérica podría haberse desarrollado a partir de un momento cálido muy concreto, el interglaciar del OIS 11, procedente de África por el Estrecho de Gibraltar (Santonja \& Pérez-González, 2010).

Dado que la correlación geomorfológica entre San Isidro (T7) y Tafesa (T9) no es viable (fig. 15), todos los hallazgos de industria achelense en las terrazas del Manzanares encajadas en la de San Isidro (T7), y en especial en la TCMZ (T9+T10), seguramente respondan a pervivencias culturales antiguas durante el desarrollo de este nivel fluvial estratigráficamente más reciente. En Tafesa la industria achelense analizada, así como la de los yacimientos de Transfesa de principios de siglo, se encuentran relacionadas con las unidades inferiores de la TCMZ. De esta forma, los depósitos correspondientes a los depósitos basales de la TCMZ $\left(\mathrm{Mz}_{1}\right.$ a $\mathrm{Mz}_{3}$ de Silva, 2003) presentan característicamente industrias cronoculturalmente asimilables a las registradas en San Isidro, pero cronológicamente más recientes. Los conjuntos líticos que pueden adscribirse al Paleolítico medio s.l. o al tránsito Paleolítico inferior-medio, solo empiezan a aparecer en los niveles superiores de la TCMZ, $\mathrm{Mz}_{4}$ y $\mathrm{Mz}_{5}$ (Silva, 2003) en la margen derecha del Manzanares. Así, el nivel de terraza T9+T10 ("Terraza Media" de Obermaier, 1925) del Manzanares, documentado en el entorno urbano de Madrid y atribuido clásicamente al final del Pleistoceno medio (aguas arriba del tramo estudiado), conservaba industrias de características musterienses o Achelense superior, en sus niveles superiores (fig. 15). En el valle inferior del Manzanares aparecen diferentes conjuntos líticos adscribibles tradicionalmente al denominado "Achelense superior", dentro de los niveles estratigráficamente más altos $\mathrm{Mz}_{3}, \mathrm{Mz}_{4}$ y $\mathrm{Mz}_{5}$ de la TCMZ (T10), como Arriaga IIa (Rus \& Vega, 1984), unidad superior de Soto e Hijos (Baena, 1992) y Perales del Río (Gamazo et al., 1983).

Otros conjuntos líticos indican posiblemente una transición al Paleolítico medio, como los yacimientos de La Gavia I (Rus, 1983) y La Gavia III (López Recio et al., 2005) situados en la margen izquierda 
del Manzanares a la altura del tramo estudiado en la T10, que pudieran interpretarse incluso como musteriense de tradición achelense (Vega et al., 1999). En este yacimiento se observan rasgos evolucionados de façonnage, con presencia de bifaces estilizados (lanceolados, cordiformes, micoquienses, etc.), algunos de pequeño formato, ausencia de esquemas de tipo triédrico, acompañado de industria con evidencias de predeterminación en la obtención de soportes-lascas, como son los procesos de talla discoide, levallois y un número importante de tanteos previos (núcleos con escasas extracciones), propio del aprovisionamiento de sílex en zonas de alta densidad de nódulos naturales y un conjunto heterogéneo de utillaje retocado sobre lasca (raederas, denticulados, perforadores, etc.).

La estandarización en la producción de lascas predeterminadas mediante modos de talla jerarquizados y programados, como son las diferentes modalidades de débitage discoide y levallois se generaliza en los conjuntos musterienses, como en el yacimiento del Hospital 12 de Octubre en los niveles superiores de la TCMZ $\left(\mathrm{Mz}_{4} \mathrm{y} \mathrm{Mz}_{5}\right)$. En este tramo final del río, las unidades más recientes de la TCMZ, $\mathrm{Mz}_{4}$ y Mz 5 (Silva, 2003, Silva et al., 2008), de cronología ya Pleistoceno superior, son las que realmente conformarán el depósito asociado a la construcción final de la TCMZ. Estos depósitos, ya relacionados con el depósito del nivel T10, se encontrarían asociados a industrias musterienses como se registra en el sector del 12 de Octubre (Silva et al., 2008). En el conjunto del valle del Manzanares se conocen conjuntos del Paleolítico medio similares, pero ya contextualizados en la terraza T11 e incluso en la T12 (Rubio et al., 2002), como La Parra, La Torrecilla (Enamorado, 1989), Atajillo del Sastre o López Cañamero (Sánchez Sastre, 1985). Ésta última (T12) responde a la terraza de $+8 \mathrm{~m}$, considerada clásicamente como la "Terraza Musteriense de Madrid" que corresponde con la "Terraza baja" de Obermaier (1925).

\section{Conclusiones}

Las terrazas estudiadas en los sectores del 12 de Octubre y Villaverde-Butarque se correlacionan morfológicamente con la terraza que contenía los yacimientos de Tafesa y Transfesa, donde se definen la totalidad de las unidades $\mathrm{Mz}$ que componen la TCMZ en el valle inferior del Manzanares (Silva, 2003). De hecho en el gráfico de la figura 15 se pueden unir mediante una teórica línea isocrona. Las discrepancias entre posiciones morfológicas y altimétricas de los diferentes niveles de terraza en los que se ubican los yacimientos analizados se debe a la existencia de importantes escalones erosivos en el cauce del propio Manzanares en su entrada en los materiales yesíferos neógenos en las inmediaciones del arroyo Butarque (Silva et al., 2008), así como a la existencia de aportes laterales, tipo glacis o aluviales, posteriores que fosilizaron las antiguas llanuras aluviales, engrosando y modificando la altimetría de los niveles fluviales durante y posiblemente también después de su desarrollo (Silva, 2003). La existencia de un sustrato evaporítico determina los fenómenos de subsidencia por disolución y colapso kárstico que quedan registrados en los depósitos. Como ya se ha indicado, la existencia de escalones de erosión remontante a lo largo del cauce y llanura de inundación actual del Manzanares (Goy et al., 1989; Bárez \& Pérez-González, 2006; Silva et al., 2008), hace difícil una correlación altimétrica fiable de todos los niveles fluviales del Manzanares entre su tramo medio (San Isidro) y su valle inferior aguas abajo del Butarque. En este trabajo se plantea una solución preliminar de cronología relativa, diferente de las correlaciones más tradicionales basadas fundamentalmente en criterios altimétricos y edáficos (fig. 15).

En relación a la cronología de la TCMZ se asignó tentativamente un rango temporal comprendido entre los estadios isotópicos OIS 10 al OIS 5 (Silva, 2003). Sin embargo, la base de esta terraza compleja en Transfesa ha sido atribuida por distintos autores (Aguirre, 1989; Santonja et al., 2001) a un rango temporal entre los estadios isotópicos OIS 13 y OIS 11, e incluso entre el OIS 11 y OIS 9 (Van der Made \& Mazo, 2001). Estas atribuciones cronológicas están fundamentalmente basadas en criterios faunísticos y especialmente ligadas a las diferentes atribuciones específicas que se han dado a los restos de cérvidos que allí aparecieron (Van der Made \& Mazo, 2001).

En la margen izquierda del valle del Manzanares del tramo objeto de estudio, los depósitos aluviales asociados a la base de la T10 en el yacimiento de La Gavia III presentan edades OSL de $85.6 \pm 8 \mathrm{ka}$ BP relacionadas con una industria de transición al Paleolítico medio (López Recio et al., 2005), asignables al final del OIS 5 o último interglaciar (13074 ka BP, Martinson et al., 1987). Estas edades son a grosso modo asimilables a las fechas TL y OSL obtenidas para la TCMZ en el yacimiento de Los 
Estragales 1, 2 y 3 (Perales del Río), $122.1 \pm 11.1$ ka BP, $90.6 \pm 9$ ka BP y $70.5 \pm 17.0 \mathrm{ka}$ BP respectivamente (Pérez-González et al., 2008), las cuales pueden correlacionarse a su vez con las unidades inferiores $\mathrm{Mz}_{1}, \mathrm{Mz}_{2}$ y $\mathrm{Mz}_{3}$ de Silva (2003). En Los Estragales 1 y 2 se han documentado conjuntos líticos amplios de unos 2.500 y más de 11.000 piezas respectivamente, que se caracterizan a grandes rasgos por la producción de lascas, núcleos de escasas extracciones y bifaciales, predominio de lascas retocadas, raederas y denticulados entre los útiles retocados y presencia testimonial de macroutillaje (Pérez-González et al., 2008). Una datación TL obtenida en los niveles inferiores de la TCMZ de un yacimiento muy próximo al anterior (EDAR-Culebro 1) arroja una edad $120.541 \pm 6.851 \mathrm{BP}$ (Manzano et al., 2011). Otras dataciones en este último yacimiento obtenidas por racemización de aminoácidos (Manzano et al., 2011) en piezas molares de Equus sp. arrojan edades de 133.280 BP y 105.100 BP, que también encajan con el esquema que se propone. Dataciones TL publicadas recientemente (Domínguez Alonso et al., 2009) en yacimientos próximos al de Villaverde-Butarque aquí analizado sitúan la base de la TCMZ $\left(\mathrm{Mz}_{1}\right)$, correspondiente a la T9 de este estudio en $>125 \mathrm{ka} \mathrm{BP}$, mientras que las unidades correspondientes a las secuencias $\mathrm{Mz}_{2}$ y $\mathrm{Mz}_{3}$ arrojan edades de $84.600 \pm 12.600 \mathrm{ka} \mathrm{BP}$ y $74.900 \pm 10.200 \mathrm{ka}$. BP que son asimilables a las obtenidas en Los Estragales por Pérez-González et al. (2008).

Las dataciones OSL procedentes de los yacimientos del 12 de Octubre (ca. 40-33 ka BP) y de Villaverde-Butarque (ca 24 y $12 \mathrm{ka} \mathrm{BP}$ ) publicadas por Silva et al. (2008), parecen mostrar un indudable grado de rejuvenecimiento, pero no sería descartable que el techo de la construcción de la T10 ya alcanzara los estadios isotópicos OIS 4 e incluso OIS 3. De hecho, las escasas dataciones numéricas existentes para el techo de las secuencias fluviales que componen la TCMZ (Pérez-González et al., 2008; Domínguez Alonso et al., 2009) asimilables a la unidad culminante $\mathrm{Mz}_{5}$ de Silva (2003) indican edades comprendidas entre $64.5+15.2 /-11.3 \mathrm{ka}$ BP y los $56.800+4.000 \mathrm{ka}$ BP que nos situarían en el final del OIS 4 o incluso el comienzo del OIS 3 ya muy avanzado el Pleistoceno superior.

De esta forma, el conjunto de dataciones disponibles hasta el momento indican claramente que la construcción de la TCMZ (T9+T10) tiene lugar casi completamente durante el Pleistoceno superior con las edades más antiguas, anteriores a los ca. 120 -
$130 \mathrm{ka}$ BP, correspondientes a la parte final del Pleistoceno medio, quizá posteriores al estadio isotópico OIS 11 como sugieren algunos autores (Van der Made \& Mazo, 2001; Santonja \& Pérez-González, 2010). Sus secuencias sedimentarias basales (T9) libran industria achelense, pero claramente culmina con industrias musterienses (T10) ya muy superado el último interglaciar (OIS 5), momento en el que en el suroeste de Francia se registran industrias adscribibles a un Musteriense de corte antiguo. Datos geológicos, geomorfológicos, arqueológicos y paleontológicos permiten inferir que durante el último interglaciar (T9: $\mathrm{Mz}_{1}, \mathrm{Mz}_{2}, \mathrm{Mz}_{3}$ ) el valle inferior del Manzanares era un amplio valle, con una llanura de inundación de hasta más de $3 \mathrm{~km}$ de anchura, recorrida por un río de curso estable, en la que existía una importante cantidad de fauna cálida-templada, que era habitualmente ocupada por grupos humanos del Paleolítico inferior en busca de recursos bióticos y abióticos, como atestiguan los numerosos yacimientos, primarios y secundarios, que en él se sitúan. Por el contrario, a partir de la fase final del último interglaciar (T10: $\left.\mathrm{Mz}_{4} \mathrm{y} \mathrm{Mz}_{5}\right)$, tanto los hallazgos líticos como faunísticos son importantes, pero fragmentarios y en su mayoría de carácter secundarios (resedimentados), indicándonos una actividad fluvial más violenta, asociada a numerosos episodios de erosión-sedimentación, que se registran en la complicada geometría "cut \& fill" de estos depósitos. Este cambio en las características morfosedimentarias de los depósitos fluviales probablemente indican el progresivo tránsito al último período glaciar. No obstante los niveles de terraza inferiores, especialmente el T11, registra de nuevo un incremento de hallazgos faunísticos y líticos, que corresponderían ya a grupos neandertales del Paleolítico medio, los cuales convivirían con especies faunísticas más frías (bisontes, rinocerontes lanudos, mamuts, etc.). Aunque en base a estos datos algunos autores (Aguirre, 1989; Silva, 2003) asignan tentativamente al OIS 4 este nivel de terraza, las escasas dataciones existentes publicadas hasta la fecha (Pérez-González et al., 2008; Domínguez Alonso et al., 2009) indican que el desarrollo de la T11 alcanza los ca. 39 - 40 ka BP, ya dentro del OIS 3.

Los resultados de las recientes excavaciones de los yacimientos paleolíticos aquí presentados parcialmente, incidiendo en la problemática geológica y del estudio tecnológico de sus conjuntos líticos, aportan datos valiosos para la reconstrucción geomorfológica del valle inferior del Manzanares durante el depósito de la "Terraza Compleja del 
Manzanares". Son necesarias nuevas dataciones de este anómalo nivel de terraza para conseguir una aproximación más precisa a la secuencia cronoestratigráfica y cronocultural del Pleistoceno en los sistemas fluviales del centro de la Península Ibérica.

\section{AGRADECIMIENTOS}

Este trabajo es una contribución del Grupo de Cuaternario Madrileño de la Asociación Española para el Estudio del Cuaternario (GQM-AEQUA) y se incluye dentro del proyecto de investigación (Ref.: HAR 2010-20151): “Algo más que bifaces: hacia la definición técnica y tecnológica de los conjuntos líticos del Pleistoceno de la región de Madrid", financiado por la Dirección General de Patrimonio Histórico de la Comunidad de Madrid. Los autores agradecen los diferentes comentarios, apreciaciones y sugerencias efectuadas por los revisores para mejorar la comprensión del texto.

\section{Referencias}

Aguirre, E. (1989). Vertebrados del Pleistoceno continental. In: Mapa y Memoria del Cuaternario de España a E. 1:1.000.000 (Pérez-González, P. Cabra, P. \& Martín Serrano, A., eds.), I.T.G.M.E., Madrid, 47-69.

Agustí, E.; Morín, J.; López Recio, M.; Escolà, M.; Urbina, D.; Silva, P.G.; Alcalde, R.; Arroyo, F.; Díaz, M.A.; Expósito, A.; González, F.M.; López Fraile, F.J.; Illán, J.; López, G.; Manzano, I.; Sanabria, P.J.; Sánchez, F.; Simón, G.; Tapias, F. \& Yravedra, J. (2009). La gestión arqueológica y paleontológica en grandes proyectos urbanísticos: el caso de la urbanización U.Z.P. 1.05 Villaverde-Barrio de Butarque. Actas de las Terceras Jornadas de Patrimonio Arqueológico en la Comunidad de Madrid (2006), 75-88.

Andrés, I. \& Aguirre, E. (1974). Un molde endocraneano de Praedama (cérvido) del Pleistoceno medio de Madrid. Cuaternaria, 18: 303-330.

Baena Preysler, J. (1992). Talleres paleolíticos en el curso final del río Manzanares. UAM Ediciones, Madrid, 134 pp.

Baena, J. \& Baquedano, I. (2004). Avance de los trabajos arqueológicos realizados en el yacimiento paleolítico de TAFESA, antiguo TRANSFESA (Villaverde, Madrid): Principales rasgos tecnológicos del conjunto lítico. Zona Arqueológica, 4: 30-47.

Baena, J.; Baquedano, I.; Benéitez, P.; Cañaveras, J.C.; Carrión, E.; Lario, J.; Martín Escorza, C.; Mazo, A.V.; Millán, A.; Sánchez, S.; Sanz, E.; Sesé, C.; Silva, P.G. \& Yravedra, J. (2010). Síntesis: Interpretación general del yacimiento de TAFESA (Madrid). In: Las huellas de nuestro pasado. Estudio del yacimiento del Pleistoceno madrileño de Tafesa (Antigua Transfesa) (Baena Preysler J. \& Baquedano Beltrán I., coords.). Zona arqueológica, 14, 189-202.

Baena, J.; Conde, C.; Carrión, E. \& Pastor, J. (2000): Paleolítico y Epipaleolítico. La Arqueología Madrileña en el final del siglo XX: desde la Prehistoria hasta el año 2000. Boletín de la Asociación Española de Amigos de la Arqueología, 39-40. XXX Aniversario (1969-1999): 81-104.

Baena Preysler, J.; Rus, I.; Cuartero, F.; Martín Puig, D.; Rubio, D. \& Roca, M. (2010). Estudio tecnológico de la industria lítica del yacimiento de Las Cien Fanegas (Madrid) en el contexto Achelense de la Meseta. Cuaternario y Arqueología, Homenaje a Francisco Giles Pacheco, 71-84.

Bárez, S. \& Pérez-González, A. (2006). Terrazas fluviales del Pleistoceno inferior y medio del río Manzanares en Vaciamadrid: el perfil de Calamuecos y sus implicaciones geomorfológicas. Boletín Geológico y Minero, 117: 351-361.

Benito, G.; Gutiérrez, F.; Pérez-González, A. \& Machado, M.J. (2000). Geomorphological and sedimentological features in Quaternary fluvial systems affected by solution-induced subsidence (Ebro Basin, NE Spain). Geomorphology, 33: 209-224.

Boëda, E. (1994). Le concept Levallois: variabilité des méthodes. Monographie du Centre de Recherches Archéologiques, 9. CNRS Éditions, Paris, 280 pp.

Boëda, E. (1991). La conception trifaciale d'un nouveau mode de taille préhistorique. In: Les premiers Européens (Bonifay E., Vandermeersch B., eds.), Actes du 114 e congrès des sociétés savantes, Paris, Comité des travaux historiques et scientifiques, 251263.

Boëda, E. (1997). Technogenèse de système de production lithique au paléolithique inférieur et moyen en Europe occidentale et au Proche-Orient. Habilitation à diriger des recherches, Université de Paris X-Nanterre. 173 pp.

Boëda, E.; Geneste, J.M. \& Meignen L. (1990). Identification de chaînes opératoires lithiques du Paléolithique ancien et moyen, Paléo, 2: 4380.

Bourguignon, L. (1996). La conception de débitage Quina. Quaternaria Nova, VI: 149-166.

Carbonell, E.; Guilbaud, M. \& Mora, R. (1983). Utilización de la lógica analítica para el estudio de tecnocomplejos a cantos tallados. Cahier Noir, 1: 3-79.

Conde, C.; Baena, J. \& Carrión, E. (2000). Los modelos de explotación de los recursos líticos durante el Pleistoceno de la región de Madrid. SPAL, 9: 145-166.

Cuartero, F. (2004). Tecnología lítica en Cova Bolomor IV: ¿una economía de reciclado? Saguntum, 39: 27-44.

Cuartero, F.; López Recio, M.; Lázaro Lázaro, A.; Martín Puig, D.; Morín de Pablos, J.; Tapias Gómez, F. \& Silva, P.G. (2007). La industria lítica de la excavación del 12 de octubre (estación 2 de la prolongación de la línea 3 de metro). Resultados preliminares. Actas de las Segundas Jornadas de Patrimonio Arqueológico en la Comunidad de Madrid (2005), 330-333.

Chevrier, B. (2006). De l'Acheuléen méridional au technocomplexe trifacial: la face cachée des industries du Bergeracois. Apport de l'analyse technologique de l'industrie lithique de Barbas I C'4 sup (Creysse, Dordogne). Gallia Préhistoire, 48: 207-252.

Delagnes, A. (1997). L'industrie lithique de la série B du Pucheuil. In: Paléolithique moyen en pays de Caux 
(Delagnes, A. \& Ropars, A., eds.), Documents d’Archéologie Française, 56, 59-130.

Domínguez Alonso, R.M.; Arcos Fernández, S.; Ruiz Zapata, B. \& Gil García, M.J. (2009). Nuevos datos sobre la Terraza compleja de Butarque en Villaverde Bajo. Actas de las Cuartas Jornadas de Patrimonio Arqueológico en la Comunidad de Madrid. Los primeros pobladores: Arqueología del Pleistoceno (2007), 339-343.

Enamorado, J. (1989). La Torrecilla y La Parra: análisis de la industria lítica de dos yacimientos de época paleolítica en el valle del Manzanares. Madrid. Boletín del Museo Arqueológico Nacional, 7: 9-27.

Forestier, H. (1993). Le clactonien: mise en application d'une nouvelle méthode de débitage s'inscrivant dans la variabilité des systèmes de production lithique du paléolithique ancien. Paléo, 5: 53-82.

Fourloubey, C. (1996). La production de raclettes au Chatenet (Saint-Front de Pradoux, Dordogne). Paléo, 8: 269-275.

Gaibar Puertas, C. (1974). Descubrimiento de la terraza würmiense en la margen izquierda del río Manzanares: aportaciones paleoclimáticas. Nuevos restos y testimonios de madrileño hombre prehistórico y protohistóricos. Estudios Geológicos, 30: 235-252.

Gamazo, M.; Cobo, A. \& Martínez de Merlo, A. (1983). El yacimiento achelense de Perales del Río (campañas de excavación 1980 y 1981). Homenaje al Profesor M. Almagro Basch, I. Ministerio de Cultura, Madrid, 95105.

Geneste, J.M. \& Plisson, H. (1996). Production et utilisation de l'outillage lithique dans le Moustérien du Sudouest de la France. Les Tares à Sourzac, vallée de 1'Isle, Dordogne. In: Reduction Processes for the European Mousterian. Proceedings of the International Round Table (Bietti, A. \& Grimaldi, S., eds.). Quaternaria Nova, 6: 149-166.

Giner, J.L.; De Vicente, G.; Pérez-González, A.; Sánchez Cabañero, J. \& Pinilla, L. (1996). Crisis tectónicas cuaternarias en la Cuenca de Madrid. Geogaceta, 20: 842-845.

Gómez Hernanz, J.; Márquez Mora, B.; Nicolás Checa,

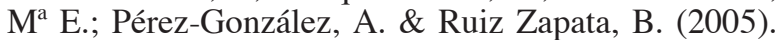
San Isidro (Madrid): 1862-2002. Nuevos hallazgos paleolíticos en la terraza de $+30 \mathrm{~m}$ del río Manzanares. Trabajos de Prehistoria, 62: 157-164.

Goy, J.L.; Pérez-González, A. \& Zazo, C. (1989). Cartografía y Memoria del Cuaternario, Hoja 19-22 (Madrid). Mapa Geológico de España 1:50.000. MAGNA. Servicio de Publicaciones del Ministerio de Industria, Madrid.

Guerrero, J.; Gutiérrez, F. \& Lucha, P. (2008). The impact of halite dissolution subsidence on fluvial terrace development. The case study of the Huerva River in the Ebro Basin (NE Spain). Geomorphology, 100: 164179.

Imperatori, L. (1955). Documentos para el estudio del Cuaternario madrileño: fenómenos de crioturbación en la terraza superior del Manzanares. Estudios Geológicos, 11: 139-149.
López Recio, M.; Manzano Espinosa, I.; Romero Salas, H.; Escalante García, S.; Pérez-González, A.; Conde Ruiz, C.; Velázquez Rayón, R.; Baena Preysler, J. \& Carrión Santafé, E. (2005). Caracterización geoarqueológica de los depósitos cuaternarios del arroyo de la Gavia (cuenca del río Manzanares, Madrid). In: Geoarqueología y Patrimonio en la Península Ibérica y el entorno mediterráneo (Santonja, M., Pérez-González, A. \& Machado, M.J., eds.). ADEMA, Soria, 261272.

López Recio, M.; Silva, P.G.; Alcalde, R.; Cuartero, F.; Expósito, A.; Lázaro, A.; González, F.M.; Manzano, I.; Martín, D.; del Moral, B.; Morín, J.; Sánchez, F.; Simón, G. \& Tapias, F. (2007): Los yacimientos paleolíticos del 12 de Octubre y Villaverde-Barrio de Butarque (Madrid) y su contextualización geológica en el valle inferior del río Manzanares. In: Contribuciones al Estudio del Período Cuaternario (Lario, J. \& Silva, P.G., eds.). Aequa, Ávila, 115-116.

López Recio, M.; Silva, P.G.; Cuartero, F.; Martín, D.; Tapias, F.; Alarcón, A.; González, F.M.; Lázaro, A.; Morín, J.; Yravedra, J.; Burjachs, F. \& Expósito, I. (2011): El yacimiento paleolítico del 12 de Octubre (Villaverde, Madrid). Actas de las Quintas Jornadas de Patrimonio Arqueológico en la Comunidad de Madrid. Los primeros pobladores: Arqueología del Pleistoceno (2008), 225-239.

López Recio, M.; Silva, P.G.; Tapias, F.; Fernández, C.; Morín, J.; Canales, Mª.; Cuartero, F.; Martín, D.; Lázaro, A.; Alcalde, MR.; Arroyo, F.; del Moral, B.; Dones, V.; González, F.M.; Agustí, E.; Burjachs, F.; Expósito, I.; Escalante, S.; Simón, G.; Cuezva, S.; Inclán, Y.; Alarcón, A.; de Arcos, P.; Escolà, M.; Gómez, J.; González, L.; Illán, J.M.; Sánchez, F. \& Víctores, R. (2006). Prolongación de la Línea 3 de Metro de Madrid de Legazpi a San Cristóbal de los Ángeles. El Patrimonio Arqueológico y Paleontológico en las obras de Ampliación de Metro de Madrid 2003-2007. MINTRA, Comunidad de Madrid, Madrid, 441-457.

Manzano, I.; Expósito, A.; Pérez-González, A.; Soto, E.; Sesé, C.; Yravedra, J.; Ruiz Zapata, B.; Millán, A.; Beneitez, P.; Torres, T.; Mondéjar, J.A.; Zarco, E.; Sánchez, H.; Citores, A.; Ramos, M. \& Rodríguez, A. (2011). El yacimiento arqueo-paleontológico de E.D.A.R. Culebro 1 (Estación Depuradora de Aguas Residuales de la cuenca baja del arroyo Culebro. Ministerio de Medio Ambiente. Confederación Hidrográfica del Tajo). Actas de las Quintas Jornadas de Patrimonio Arqueológico en la Comunidad de Madrid. Los primeros pobladores: Arqueología del Pleistoceno (2008), 213-224.

Martínez de Merlo, A.M. (1984). El Paleolítico superior del valle del Manzanares: el yacimiento de El Sotillo. Boletín del Museo Arqueológico Nacional, 1: 47-68.

Martinson, D.G.; Pisias, N.G.; Hays, J.D.; Imbrie, J.; Moore, T.C. JR. \& Shackleton, N.J. (1987). Age dating and the orbital theory of ice ages. Development of a high resolution 0 to 300,000 year chronoestratigraphy. Quaternary Research, 27: 1-29. 
Meléndez, B. \& Aguirre, E. (1957). Los elefantes de las terrazas del Manzanares y del Jarama. Actas del V Congreso Internacional INQUA. CSIC. 567

Meléndez, B. \& Aguirre, E. (1958). Hallazgo de Elephas en la terraza media del río Manzanares (Villaverde, Madrid). Las Ciencias, 23: 597-605.

Merrits, D. J.; Wohl, V.K.R. \& Ellen, E. (1994). Long River profiles, tectonism and eustasy: a guide to interpreting fluvial terraces. In: Tectonics and Topography, Part 2 (M.A. Ellis, M.A. \& Merrits, D.J. eds.). Journal of Geophysical Research, 99, B7: 14,031-14,051. Paper 94JB00857.

Morala, A. (1993). Technologie lithique du Magdalénien ancien de l'abri Casserole (Les Eyzies de Tayac, Dordogne). Paléo, 5: 193-208.

Mosquera, M. (1989). Análisis y secuencias de talla lítica sobre sílex. Aportación experimental a los métodos de talla en volumen y marginal centrípeto. Tesis de licenciatura, Universidad Complutense de Madrid, $184 \mathrm{pp}$.

Obermaier H. (1925): El hombre fósil. Comisión de Investigaciones Paleontológicas y Prehistóricas, $2^{\text {a }}$ edición, 9, 473 pp.

Pelegrin, J. (2000). Les techniques de débitage laminaire au Tardiglaciaire: critères de diagnose et quelques réflexions. Congrès L'Europe Centrale et Septentrionale au Tardiglaciaire: Confrontation des modèles régionaux de peuplement. Table-ronde internationale, Nemours, France (1997), 73-86. Mémoires du Musée de préhistoire d' Ile-de-France.

Peresani, M. (ed.) (2003). Discoid Lithic Technology. Advances and implications. BAR International Series 1120. Archaeopress, Oxford, 275 pp.

Pérez-González, A. (1971). Estudio de los procesos de hundimiento en el valle del río Jarama y sus terrazas (nota preliminar). Estudios Geológicos, 37: 317-324.

Pérez-González, A. (1982). Neógeno y Cuaternario de la Llanura Manchega y sus relaciones con la Cuenca del Tajo. Tesis doctoral, Universidad Complutense de Madrid, 787 pp.

Pérez-González, A. (1994). Depresión del Tajo. In: Geomorfología de España (Gutiérrez Elorza, M. ed.). Ed. Rueda, Madrid, 389-436.

Pérez-González, A.; Rubio Jara, S.; Panera, J. \& Uribelarrea, D. (2008). Geocronología de la sucesión arqueoestratigráfica de Los Estragales en la Terraza Compleja de Butarque (Valle del río Manzanares, Madrid). Geogaceta, 45: 39-42.

Pérez-González, A. \& Uribelarrea, D. (2002). Geología del Cuaternario en los valles fluviales del Jarama y Manzanares en las proximidades de Madrid. In: Bifaces y Elefantes. La investigación del Paleolítico Inferior en Madrid (Panera, J. \& Rubio, S. coords.). Zona Arqueológica, 1. Museo Arqueológico Regional, Alcalá de Henares, 302-317.

Pinilla, L.; Pérez-González, A.; Sopeña, A. \& Parés, A. (1995). Fenómenos de hundimientos sinsedimentarios en los depósitos cuaternarios del río Tajo en la Cuenca de Madrid (Almoguera-Fuentidueña de Tajo). In: Reconstrucción de paleoambientes y cambios climáti- cos durante el Cuaternario (Aleixandre Campos, T. \& Pérez-González, A., eds.). Monografías Centro de Ciencias Medioambientales, 3. CSIC, Madrid, 125-140.

Prost, D.C. (1988). Essai d'étude sur les mécanismes d'enlévement produits par les façons agricoles et le piétinement humain sur des silex expérimentaux. In: Industries Lithiques. Tracéologie et Technologie lithique (Beyries, S., ed.). Cahiers de L'U.R.A., 28: 37-41.

Quero, S. (1994). Excavación del elefante de Orcasitas (Madrid). Estudios de Prehistoria y Arqueología Madrileñas, 9: 11-16.

Querol, M. A. \& Santonja, M. (eds.) (1979). El yacimiento achelense de Pinedo (Toledo). Excavaciones Arqueológicas en España, 106. Ministerio de Cultura, Madrid. 181 pp.

Révillion, S. (1995). Technologie du débitage laminaire au Paléolithique moyen en Europe septentrionale: état de la question. Bulletin de la Société Préhistorique Française, 92: 425-442.

Riba, O. (1957). Terrases du Manzanares et du Jarama aux environs du Madrid. Libro-Guía Exc. C-2, V INQUA Int. Cong., Madrid-Barcelona, $55 \mathrm{pp}$.

Rubio, S.; Panera, J.; Martos, J.A.; Santonja, M. \& Pérez-González, A. (2002). Revisión crítica y síntesis del Paleolítico de los valles de los ríos Manzanares y Jarama. In: Bifaces y Elefantes. La investigación del Paleolítico Inferior en Madrid (Panera, J. \& Rubio, S., coords.). Zona Arqueológica, 1, Museo Arqueológico Regional, Alcalá de Henares, 338-355.

Rus, I. (1983). El Paleolítico en el Valle del Manzanares: más de un siglo de estudios. Revista de Arqueología, 32: 7-15.

Rus, I. (1987). El Paleolítico. 130 años de Arqueología Madrileña. Real Academia de Bellas Artes de San Fernando, Madrid, 20-43.

Rus, I. \& Enamorado, J. (1991). Flint supply in the Manzanares valley: the acheulian site of Arriaga (Madrid, Spain). Abstracts of the VI Flint International Symposium. ITGME, Madrid, 267-271.

Rus, I. \& Querol, Ma .A. (1981). El arenero de Oxígeno: Bifaces, Hendedores y Triedros conservados en el Museo Arqueológico Nacional. Trabajos de Prehistoria, 38: 39-67.

Rus, I.; Roquero, E.; Mazo, A. \& Enamorado, J. (1993). Terrazas del Pleistoceno Medio en la Cuenca del Tajo y fauna e industria asociada. 3 Reuniao do Quaternario Ibérico. Resumos, 86. AEQUA, Coimbra.

Rus, I. \& Vega, G. (1984). El yacimiento de Arriaga II: problemas de una definición actual de los suelos de ocupación. Primeras Jornadas de Metodología e Investigación Prehistórica (Soria, 1981). Ministerio de Cultura, Madrid, 387-404.

Sánchez, S.; Silva, P.; Lario, J.; Cañaveras, J. \& Sanz, E. (1996). Geología, geomorfología y sedimentología de los depósitos cuaternarios del yacimiento de Tafesa (Villaverde Bajo, Madrid). Informe inédito.

Sánchez Sastre, J. (1985). Los yacimientos paleolíticos de El Atajillo, Atajillo del Sastre y López Cañamero en el valle del Manzanares. Estudios de Prehistoria y Arqueología Madrileñas, 4: 75-118. 
Sancho, C.; Peña, J.L.; Benito, G.; Lewis, C.; Mcdonald, E. \& Rhodes, E. (2005). Descargas glaciares, aluvionamiento y karstificación en la cuenca del río Gállego (Pirineos y Depresión del Ebro). In: Cuaternario mediterráneo y poblamiento de homínidos (Rodríguez, J.; Finlayson, C. \& Giles, F. eds.). Abstract de la VI Reunión del Cuaternario Ibérico (Gibraltar), 33-34.

Santonja, M. (1976). Industrias del Paleolítico Inferior en la Meseta Española. Trabajos de Prehistoria, 33: 121-164.

Santonja, M. (1977). Los bifaces del Cerro de San Isidro conservados en el Museo Arqueológico Nacional. Revista de Archivos, Bibliotecas y Museos, 80: 147182.

Santonja, M. (1984-85). Los núcleos de lascas de la Meseta Central Española. Zephyrus, 37-38: 17-33.

Santonja, M. \& Pérez-González, A. (1997). Los yacimientos achelenses en terrazas fluviales de la Meseta Central española. In: Cuaternario Ibérico (Rodríguez Vidal, J., ed.). Huelva, 224-234.

Santonja, M. \& Pérez-González, A. (2001). El Paleolítico Inferior en el interior de la Península Ibérica. Un punto de vista desde la geoarqueología. Zephyrus, 5354: 27-77.

Santonja, M. \& Pérez-González, A. (2010). "Mid-Pleistocene Acheulean Industrial Complex in the Iberian Peninsula". Quaternary International, 213: 154-161.

Santonja, M.; Pérez-González, A.; Vega, G. \& Rus, I. (2001). Elephants and stone artifacts in the Middle Pleistocene terraces of the Manzanares river (Madrid, Spain). The World of Elephants. Proceedings of the I International Congress (Roma), 597-601.

Santonja, M. \& Querol, M ${ }^{\mathrm{a}}$ A. (1980). Las industrias achelenses en la región de Madrid. In: Ocupaciones achelenses en el valle del Jarama (Santonja, M.; López, N. \& Pérez-González, A., eds.). Diputación Provincial de Madrid, Madrid, 29-48.

Sesé, E. \& Soto, C. (2000). Vertebrados del Pleistoceno de Madrid. In: Patrimonio Paleontológico de la Comunidad de Madrid (Morales, J. coord.). Arqueología, Paleontología y Etnografía, 6. Comunidad de Madrid, Madrid, 216-243.

Silva, P.G. (1988). El Cuaternario del sector centromeridional de la Cuenca de Madrid: Aspectos geomorfológicos y neotectónicos. Tesis de Licenciatura, Universidad Complutense de Madrid, 143 pp.

Silva, P.G. (2003). El Cuaternario del valle Inferior del Manzanares. Estudios Geológicos, 59: 107-131.

Silva, P.G.; Cañaveras, J.C.; Sánchez-Moral, S.; Lario, J. \& Sanz, E. (1997). 3D soft-sediment deformation structures: evidence for Quaternary seismicity in the Madrid basin, Spain. Terranova, 9: 208-212.

Silva, P.G. \& González Hernández, F.J. (e.p.). Cartografía y memoria geológica del Cuaternario y Geomorfología. Hoja de Getafe (19-23). Mapa Geológico de España escala 1:50.000 $3^{\text {a }}$ Serie (MAGNA). IGME, Madrid.

Silva, P.G.; Goy, J.L. \& Zazo, C. (1988a). Neotectónica del sector centro-meridional de la Cuenca de Madrid. Estudios Geológicos, 44: 415-427.

Silva, P.G.; Goy, J.L. \& Zazo, C. (1988b). Evolución geomorfológica de la confluencia de los ríos Jarama y
Tajuña durante el Cuaternario (Cuenca de Madrid, España). Cuaternario y Geomorfología, 2: 125-133.

Silva, P.G.; Hoyos, M.; Goy, J.L.; Zazo, C.; Rus, I. \& Querol, N. (1989). Valles del Manzanares-Jarama. Libro-Guía Exc. C-2. $2^{\text {a }}$ Reun. Int. Cuaternario Ibérico. Madrid, 42 pp.

Silva, P.G.; López Recio, M.; González Hernández, F.M.; Tapias, F.; Alarcón, A.; Cuartero, F.; Expósito, A.; Lázaro, I.; Manzano, I.; Martín, D.; Morín, J. \& Yravedra, J. (2008). Datos geoarqueológicos de la terraza compleja del Manzanares entre el sector del 12 de Octubre y la desembocadura del arroyo Butarque (Villaverde, Madrid). Cuaternario y Geomorfología, 22: 47-70.

Silva, P.G.; Mather, A.E.; Harvey, A.M.; Goy, J.L. \& Zazo, C. (1995). Controles en la evolución y desarrollo del drenaje en zonas tectónicamente activas: el caso del río Mula (región de Murcia, SE España)". Revista de la Sociedad Geológica de España, 9: 269-283.

Silva, P.G.; Palomares, M.; Rubio, F.; Goy, J.L.; Hoyos, M.; Martín-Serrano, A.; Zazo, C. \& Alberdi, M.T. (1999). Geomorfología, Estratigrafía, Paleontología y Procedencia de los depósitos arcósicos cuaternarios de la Depresión Prados-Guatén (SW Madrid). Cuaternario y Geomorfología, 13: 79-96.

Soressi, M. (2002). Le Moustérien de tradition acheuléenne du sud-ouest de la France. Discussion sur la signification du faciès à partir de l'étude comparée de quatre sites: Pech-de-l'Azé I, Le Moustier, La Rochette et la Grotte XVI. Thèse de l'Université Bordeaux I, $344 \mathrm{pp}$.

Soto, E. \& Sesé, C. (1987). Mamíferos del Pleistoceno del municipio de Madrid. Estudios de Prehistoria y Arqueología Madrileñas, 5: 11-35.

Tringham, P. C.; Cooper, G.; Odell, B.; Voytek \& Whitman, A. (1974). Experimentation in the formation of edege damage: a new approach to lithic analysis". Journal of Field Archaeology, 1: 171-196.

Turq, A. (1989). Approche technologique et économique du facies moustérien de type Quina. Bulletin de la Société Préhistorique Française, 86: 244-256.

Vega, G.; Raposo, L. \& Santonja, M. (1999). Environments and settlement in the Middle Palaeolithic of the Iberian Peninsula. In: The Middle Palaeolithic Occupation of Europe (Roebroeks, W. \& Gamble, C., eds.), University of Leiden, 23-48.

Van der Made, J. \& Mazo, A. (2001). Spanish Pleistocene proboscidean diversity as a function of climate. The World of Elephants. Proceedings of the $1^{\text {st }}$ International Congress (Roma), 214-218.

Wernert, P. \& Pérez de Barradas, J. (1925). El yacimiento paleolítico de San Isidro. Estudio bibliográfico-crítico. Revista Biblioteca, Archivo y Museo del Ayuntamiento de Madrid, 2: 31-68.

Wohl, V.K.R.; Ellen E.; Merrits, J. \& David M. (2001). Bedrock Channel Morphology. Geological Society of America Bulletin, 113: 1205-1212.

Recibido el 9 de junio de 2010 Aceptado el 4 de marzo de 2011 Publicado online el 7 de octubre de 2011 